Portland State University

PDXScholar

$5-14-1974$

\title{
An investigation of the development of the phonemes /t/and / $/$ / in the speech of preschool children.
}

Glenn Douglas Weybright

Portland State University

Follow this and additional works at: https://pdxscholar.library.pdx.edu/open_access_etds

Part of the Speech Pathology and Audiology Commons

Let us know how access to this document benefits you.

\section{Recommended Citation}

Weybright, Glenn Douglas, "An investigation of the development of the phonemes /t/and /k/ in the speech of preschool children." (1974). Dissertations and Theses. Paper 2308.

https://doi.org/10.15760/etd.2305

This Thesis is brought to you for free and open access. It has been accepted for inclusion in Dissertations and Theses by an authorized administrator of PDXScholar. Please contact us if we can make this document more accessible: pdxscholar@pdx.edu. 
AN ABSTRACT OF THE THESIS OF Glenn Douglas Weybright for the Master of Science in Speech: Emphasis in Speech Pathology/Audiology presented May 14, 1974. Title: An Investigation of the Development of the Phonemes / $/ /$ and $/ \mathrm{k} /$ in the speech of Preschool Children.

APPROVED BY MEMBERS OF THE THESIS COMMITTEE:

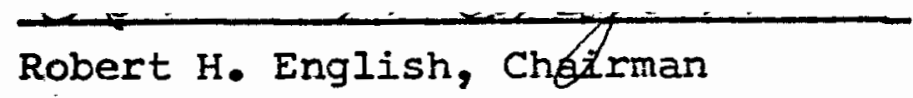

Robert I. Casteel

James A. McCartney

Research regarding children's instrumental articulation development has provided the speech clinician with schedules of speech sound development. These developmental tables list ages when specific phonemes are mastered by normal children. Such schedules tend to give the impression that certain sounds must be developed before others can 
occur. Menyuk (1972) has expressed a similar point of view regarding phonemes $/ t /$ and $/ \mathrm{k} /$. She has hypothesized:

1) that phoneme / $/$ / must develop before phoneme / $/$; and

2) that sound element initial $\langle t\rangle$ is mastered at an earlier age than initial $4 k 7$. The present investigation was designed to operationally test the validity of Menyuk's observations.

The primary purpose of this study was to determine the ages at which phonemes $/ t /$ and $/ k /$ are mastered by normally developing children, thereby obtaining the order in which these phonemes are learned. A secondary purpose was to present an alternative to the concept of mastery of speech sounds by determining the ages at which children acquire phonemes $/ t /$ and $/ \mathrm{k} /$. Four specific questions were posed by this study:

1. Is phoneme / $t /$ mastered before phoneme $/ \mathrm{k} /$ ?

2. Is sound element initial [E] mastered before initial $\angle \mathrm{k}\rangle$ ?

3. What is the order of mastery of the remaining two sound elements of each phoneme?

4. What is the order of acquisition of the two phonemes?

Seventy children, ranging in ages from 2.5 to 6 years, were selected as subjects from Portland-area preschools. Selection was based on age, sex, socioeconomic status, auditory acuity, and intelligence. Each child was presented with pictures designed to elicit phonemes /t/ and /k/ in three positions within words: initial, medial, and 
final. Ages of mastery were obtained for individual sound elements and for the "complete" phonemes $/ t /$ and $/ \mathrm{k} /$. Mastery of a specific sound element of $/ t /$ or $/ k /$ was indicated if 75 per cent of subjects within a given age group correctly produced the target sound. The phonemes $/ t /$ and $/ \mathrm{k} /$ were labeled as mastered if three sound elements (initial, medial, final) were correctly produced by 75 per cent of all subjects at a particular age level. Mastery of phonemes also was assessed by excluding medial sound elements from analysis. Acquisition was determined by noting the age where at least 51 per cent of the subjects correctly produced phonemes $/ t /$ and $/ \mathrm{k} /$. Analysis of data from the present investigation produced the following results:

1. Phoneme $/ \mathrm{k} /$ was mastered at an earlier age than $/ t /, / k /$ at 3 to 3.5 years and $/ t /$ beyond 6 years. With medial sound elements excluded from analysis, the order of mastery remained the same, $/ \mathrm{k} /$ prior to $/ t /$. In this case, phoneme $/ \mathrm{k} /$ was mastered at age 2.5 to 3 , while /t/ was mastered at age 3.5 to 4 .

2. Sound elements initial $[t]$ and $[k]$ were mastered at the same age level, 2.5 to 3 years.

3. Sound element medial $\langle k\rangle$ was mastered at age level 2.5 to 3 years, while medial $[t]$ was mastered at 4 to 4.5 years. Mastery of final $[\mathrm{k}]$ was achieved at 2.5 to 3 years, while final $[t]$ was mastered one year later, at 3.5 to 4 years.

4. Both phonemes $/ t /$ and $/ k /$ met acquisition criteria at the same age level, 2.5 to 3 years. 
In conclusion, results of the present investigation tend to contraindicate the two hypotheses made by Menyuk (1972) relative to mastery of phonemes $/ t /$ and $/ \mathrm{k} /$. 


\section{AN INVESTIGATION OF THE DEVELOPMENT OF THE PHONEMES / $/$ / AND / $/$ IN THE SFEECH OF PRESCHOOL CHILDREN}

by

GLENN DOUGLAS WEYBRIGHT

A thesis submitted in partial fulfillment of the requirements for the degree of

MASTER OF SCIENCE in

SPEECH: EMPHASIS IN SPEECH PATHOLOGY/AUDIOLOGY

Portland State University 1974 
TO THE OFFICE OF GRADUATE STUDIES AND RESEARCH:

The members of the Committee approve the thesis of Glenn Douglas Weybright presented May 14, 1974.

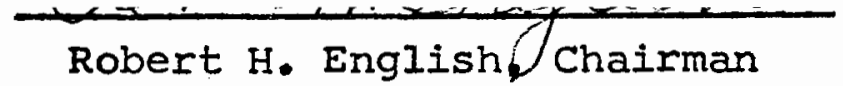

Robert L. Casteel



\section{APPROVED:}

Robert w. Vogelsahg, Head, Department of Speech

David T. Clark, Dean of Graduate studies 


\section{ACKNOWLEDGEMENTS}

This study could not have been completed without the support, assistance, and encouragement of a number of people.

I am grateful to Dr. McKenzie Buck and Dr. Warren Johnson of the Portland Center for Hearing and Speech for their cooperation in allowing me time to finish this study. Dr. Buck and the staff of the Center are to be especially thanked for their confidence that this study would be successfully completed.

Grateful acknowledgement is extended to Mrs. Moreland Anderson, who typed the final copy of this study on short notice and at a non-inflationary price. Her skill and the patience of her family are much appreciated.

Sincere gratitude also is expressed to the directors and children of the preschools with whom I worked. Their cooperation made the selection and testing of subjects an enjoyable experience.

I am grateful for the technical help offered by Dr. James McCartney, who suggested specific audiological assessment procedures and Dr. Jack Hegrenes, who dealt with sample selection and statistical analysis. Dr. Hegrenes is to be especially thanked for giving so freely of his time and expertise during several "last-minute" consultations.

Special gratitude is expressed to Dr. Robert English and Dr. Robert Casteel. As chairman of my thesis committee, 
Dr. English unfailingly encouraged and guided this study and its author. I an deeply grateful for his constructive criticism regarding writing style; for his unselfish giving of hours of his own time; and for his unique ability to quickly solve many logistical problems. My deepest appreciation also is extended to Dr. Casteel for suggesting this study; for sharing his knowledge of articulation development and assessment, and for his constant support and encouragement.

Finally, I would like to thank my family for their continuing optimism and encouragement in spite of an oftentense son and husband. My mother's confidence in me was a tremendous help in completing this study. The help provided me by my wife, Debbie, included not only warm encouragement, but also months of typing rough drafts of the paper. Her skill in preparing tables and figures, as well as her willingness to put up with long hours and short weekends, will always be remembered. 
TABIE OF CONTENTS

PAGE

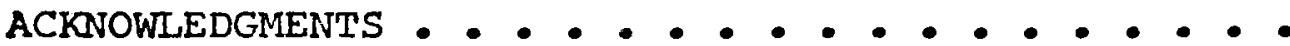

IIST OF TABLES $\bullet \cdot \cdot \cdot \cdot \cdot \cdot \cdot \cdot \cdot \bullet \cdot \bullet \cdot \cdot \cdot \cdot \cdot$

viii

IIST OF FIGURES • $\bullet \cdot \bullet \cdot \bullet \cdot \bullet \cdot \bullet \cdot \bullet \cdot \bullet \cdot \bullet \cdot \bullet \cdot \bullet$

$\mathbf{x}$

CHAPTER

I INTRODUCTION AND STATEMENT OF THE PROBLEM • •

Introduction $\bullet \cdot \cdot \cdot \cdot \cdot \cdot \cdot \cdot \cdot \cdot \cdot \cdot \cdot \cdot \cdot$ I

Statement of the Problem . . . . . . .

Specific Questions to be Answered . . . . . 3

Definitions $\ldots$

II REVIEW OF THE IITERATURE $\bullet \bullet \cdot \bullet \cdot \bullet \cdot \bullet \bullet \bullet-9$

Developmental Studies . . . . . . . . . 10

The Wellman et al. Study

The Poole Study

The Templin Study

Results of the Three Developmental Studies

Compared with Menyuk's Hypotheses Relative

to Phonemes $/ \mathrm{t} /$ and $/ \mathrm{k} /$ - $\cdot \bullet \cdot \bullet \cdot \bullet \cdot \bullet \cdot$

Traditional Articulation Assessment . • • •

Medial Position

Imitative versus spontaneous Testing

Mastery: A New Point of view . - . . - •

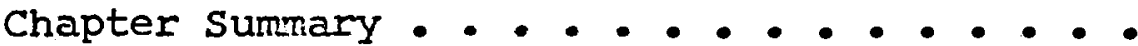


Age

Socioeconomic status

Inteligence

Auditory Acuity

Instrumentation $\cdot \cdot \cdot \cdot \cdot \cdot \cdot \cdot \cdot \cdot \cdot \cdot \cdot \cdot \cdot$

Investigator Reliability

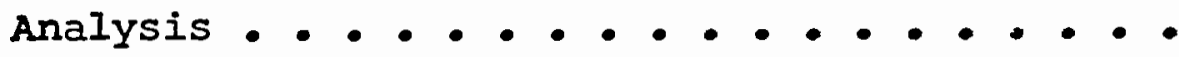

Mastery of Sound Elements and Phonemes

Acquisition of Phonemes / $/ /$ and $/ \mathrm{k} /$

Target Words Presented by Modeling

Production of a Two-Syllable Form of the Eliciting word "Potato"

IV RESULTS AND DISCUSSION OF RESULTS - • • • •

The Order of Mastery of Phonemes / $t /$ and

$/ \mathrm{k} /$, Set One: Ages Calculated by Including the Medial Sound Elements

The order of Mastery of Phonemes / $t /$ and $/ \mathrm{k} /$, Set Two: Ages Calculated by Excluding the Medial Sound Elements

The Order of Mastery of Sound Elements Initial $[\mathrm{t}]$ and $[\mathrm{k}]$

The Order of Mastery of the Remaining Two Sound Elements of Each Phoneme

The Order of Acquisition of Phonemes / $t /$ and $/ \mathrm{k} /$ 
vii

CHAPTER

PAGE

Target Words Presented by Modeling

Production of a Two-syllable Form of the Eliciting word "Potato"

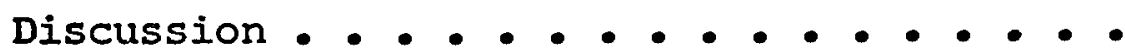

The Order of Mastery of Phonemes / $t /$ and $/ \mathrm{k} /$

Mastery of Sound Elements Initial $\measuredangle \succeq]$ and Initial $\Delta \mathrm{k}$

Mastery of Sound Elements Medial and Final $\langle Z\rangle$ and $\langle\mathrm{k}\rangle$

Acquisition of Phonemes $/ t /$ and $/ k /$

Medial Position

Target Words Presented by Modeling

Production of a Two-Syllable Form of the Eliciting word "Potato"

v SUMMARY AND IMPLICATIONS • - • • • • • • • •

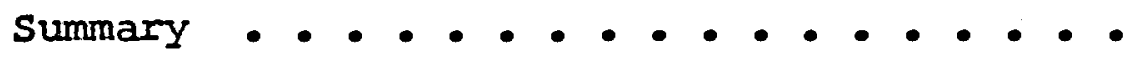

Implications . • - • • • • • • • • • •

100

BIBLIOGRAPHY

103

APPENDIX A: A List of the Preschools Utilized in the Present Investigation. . .

106

APPENDIX B: Introductory Letter to the Selected

Preschools. . . .

APPENDIX C: Test Record Form. - . - . . . 109

APPENDIX D: Eliciting and Descriptive Sentences for each Target Word. . . . . .

APPENDIX E: The Presence or Absence of a Characteristic/t/ in the Word "skating". 


\section{LIST OF TABLES}

TABLE

PAGE

I Development of the Instrumental Use of Consonants /t/ and /k/ (From Powers, 1957) •. 27

2 Comparison of the Ages at which subjects in the Three Developmental Studies Mastered $/ t /$ and $/ \mathrm{k} /$ : Sound Elements and Phonemes $\bullet \bullet \bullet \bullet \bullet \bullet \bullet \bullet \bullet \bullet \bullet \bullet \bullet \bullet \bullet \bullet \bullet \bullet \bullet$

3 Comparison of the Ages at which subjects in the Three Developmental Studies Mastered $/ t /$ and $/ \mathrm{k} /$ : A) with Medial Sound Elements Included in the Analysis; and B) with Medial Sound Elements Excluded . .

4 Proposed Normative Schedule for the Development of Consonant Sounds (From Sander, 1972) • • 45

5 Mean Age of Children in Each Age Group • • - 53

6 Mean PPVT IQ Equivalents Listed by Age

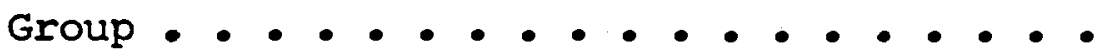

7 Percentage of Children at Each Age Level who

Correctly Produced AII Sound Elements

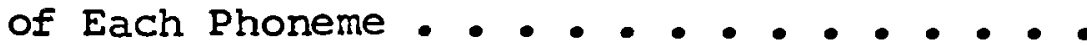

8 Percentage of Children at Each Age Level who

Correctly Produced Two Sound Elements (Initial and Final) of Each Phoneme • • • 
9 Percentage of Children at Each Age Level

Who Correctly Produced Each Sound

Element - . - • • • - • • • • • 72

10 Percentage of Children at Each Age Level

Who Correctly Produced At Least Two of

Three Sound Elements (Acquisition) • • • 73

11 Number and Percentage of Total Utterances

which Required Modeling • . • • • • - 75

12 Number and Percentage of Utterances which

Required Modeling, Listed by Age Level • • 76

13 Instances of Modeling Required for each Target

Word, Listed by Age Ievel . . . . . 77

14 Number and Percentage of Children in each

Age Group Who Responded with a Two-

Syllable Form of the Eliciting word

"potato" •. . . . . . . . . . . . .

15 Comparison of the Ages at which subjects in

the Three Developmental Studies and the

Present Investigation Mastered /t/ and

/k/: Sound Elements and Phonemes . • . 82

16 Target Words Utilized in the Three Developmen-

tal Studies and the Present Investigation . 
1 A Visual Demonstration of the Data Presented in Table 7 . . . . . . . . . . .

2 A Visual Demonstration of the Data Presented

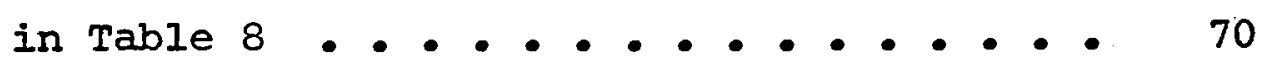

3 A Visual Demonstration of the Data Presented in Table $10 . . . \cdot . \cdot . \cdot . \cdot . \cdot . \cdot . \cdot$ 
CHAPTER I

INTRODUCTION AND STATEMENT OF THE PROBLEM

\section{INTRODUCTION}

In preparing for their first clinical experience, student speech clinicians are often given schedules of speech sound development, which list the specific phonemes of the language and the ages at which these sounds are mastered by normal children. Such schedules sometimes tend to give the novice clinician (and parents) the impression that certain sounds in the child's language must be developed before others can occur. Following such an impression, teaching the child a specific sound would have to wait until the "prerequisite" sound had developed. An example of this type of orientation toward phoneme acquisition is found in the following statements by Menyuk (1972, p. 24):

The presence of $/ t /$ is necessary for the presence of $/ k /$. . In like fashion, it is hypothesized that the child cannot acquire / $/ \mathrm{k}$ before $/ t /$, and indeed it is the case that in the acquisition of American English the initial $\langle t]$ is mastered before the initial $[\mathrm{k}]$.

Recent texts in speech sound development have tended to discuss sound acquisition in the larger context of the child's progress in learning to use his language. With this stronger emphasis on the context in which sound development takes 
place also has come a re-analysis of the major sound development studies on which age levels for specific sounds have traditionally been based. Winitz (1969), in examining the data collected by Wellman and others (1931), Poole (1934), and Templin (1957), agrees that sound development is correlated with age, and that some sounds are learned before others. He notes, however, the lack of data which would indicate that sound development proceeds in an exact, inviolate manner, or, in other words, that one sound must be mastered before another can be learned. Referring to the same problem, Irwin (1972, p. 18) writes that ". . in no sense can one sound be considered a prerequisite to the appearance of a second in the speech of any particular child."

The clinician's task in articulation intervention certainly would be made easier if there were specific "prerequisite" sounds which had to be developed before development could proceed on other sounds. For example, consider the speech clinician who finds a child omitting both /t/ and /k/ in all positions (initial, medial and final) in words. In choosing the first phoneme with which to work, the clinician might consult such sources as Irwin (1972), Powers (1972), or Van Riper (1963), who list a variety of considerations involved in making such a choice. They include the suggestion that treatment be initiated with an early-appearing phoneme, as opposed to one which develops at a later age. To determine age of appearance of the phonemes $/ t /$ and $/ k /$, the clinician could refer to literature dealing with the development of 
consonant sounds. One source examined might be Menyuk's previously cited statement indicating that phoneme / $t /$ must develop before the phoneme $/ \mathrm{k} /$. If such a relationship between these two phonemes does in fact exist, Menyuk's statement would prove essential since one would not want to waste valuable clinic time by attempting to elicit a sound which required a "prerequisite" before development could occur. On the other hand, if development of $/ \mathrm{k} /$ did not depend on first learning $/ t /$, then these phonemes could be taught in either order, or together. At the very least, especially in the case of always teaching $/ t /$ before $/ \mathrm{k} /$, the clinician should be reasonably sure of the validity of his source before using its information to develop a specific treatment program. Hence, the present study was designed to operationally test the validity of Menyuk's observations relative to phonemes $/ t /$ and $/ k /$.

\section{STATEMENT OF THE PROBLEM}

The purpose of the present study is to determine the ages at which phonemes $/ t /$ and $/ k /$ are mastered by children, thereby obtaining the order in which these phonemes are learned. A secondary purpose is to present an alternative to the concept of mastery of speech sounds by determining the ages at which children acquire the phonemes $/ t /$ and $/ k /$.

\section{SPECIFIC QUESTIONS TO BE ANSWERED}

The present investigation will examine four specific 
questions relative to the two problems stated above:

1. Is the phoneme / $t /$ mastered before the phoneme $/ \mathrm{k} /$ ?

2. Is initial $[t]$ mastered before initial $[\mathrm{k}]$ ?

3. What is the order of mastery of the remaining two sound elements of each phoneme?

4. What is the order of acquisition of the two phonemes?

\section{DEFINITIONS}

The following are descriptions of terms used operationally in this study.

\section{Acquisition}

A phoneme will be labeled as acquired by the individual child if it is produced correctly in two out of three positions within a word, i.e., initial (I), middle (M), and final (F). Group acquisition of a phoneme will be assumed if 51 per cent or more of the children tested at a specific age level correctly produce each phoneme in two out of the three positions noted above (following Sander, 1972, p. 60).

\section{Correct Production}

Correct production indicates that the sound element as it is used in words has not been omitted, distorted, nor had another sound substituted in its place. The correctly produced sound element is one that will be accepted by the listener as conforming to the standards of the general population of adult speakers and listeners of American English. 


\section{Distortion}

Distortion will be defined as an unacceptable acoustic event which is clearly not an omission or substitution of one standard sound element for another. When recording test information, a distortion will be noted by the symbol "x."

\section{Instrumental Use of Speech Sounds}

This term will be used to refer to the purposeful use of speech sounds in words, as opposed to random pre-instrumental utterances. Irwin (1972) indicates that a child's instrumental use of phonemes begins at approximately eighteen to 20 months.

\section{Mastery}

Two operational definitions of the concept of mastery of instrumental speech sounds are utilized in the design of the present study. The definitions and the developmental ages resulting from the application of the two sets of requirements are hereafter labeled as set I and set II.

Set I. A phoneme will be considered mastered if it is correctly produced in three positions within words: initial (if the sound begins a word), medial (if the sound is used in the middle of a word), and final (if the sound terminates a word). These word positions correspond to the three sound elements of each phoneme, and are further defined under sound Element. Age-group mastery of a phoneme will be assumed when at least 75 per cent of the subjects assessed at a specific age level correctly produce each phoneme in the 3 positions 
noted above.

Set II. A phoneme will be labeled mastered if it is correctly produced in two positions within words: initial and final. Mastery at a specific age level will again be assumed when at least 75 per cent of the subjects correctly produce the phoneme in initial and final positions in words.

Mastery of Sound Elements. An individual sound element will be labeled mastered if it is produced correctly within a specific word position. Age of mastery for each sound element will be determined by noting the specific age level at which the sound is first produced correctly by at least 75 per cent of the subjects.

\section{Omission}

Omission will be defined as ". - a failure to make any speech-like sound at a juncture in a word or phrase at which a phoneme of English would normally be articulated (Irwin, 1972, p. 26)." In the case of the sound elements final $[t]$ and final $[k]$, the sound element must be released. If it is not, the sound element will be scored as omitted, and the test record form will be marked with a dash (-).

\section{Phoneme}

A phoneme will be defined as a method of classifying those sound elements whose use in a particular word results in a difference in meaning. The term will be used primarily to refer to general developmental results, or, in other words, a summary of the development of the specific sound elements. 
To avoid confusion, phonemes will be indicated by slashes (//); sound elements will be noted by using brackets ( $I J)$ (Winitz, 1969). This study examines two phonemes, /t/ and $/ \mathbf{k} /$

Sound Element

A sound element will be defined as that sound which results when a phoneme is produced in a specific position within a word. When designated as belonging to a particular phoneme category, sound elements will not result in a change in word meaning. Three sound elements will be studied to determine mastery and acquisition: Initial (if the sound begins a word and is followed by a vowel sound, excluding blends such as try, twelve, clown, cracker, and guilt); medial (if the sound is used in the middle of a word, does not occur in a consonant blend context, and is the initiating consonant of the second syllable or the terminating consonant of the first syllable, followed but not necessarily preceeded by a vowel sound); and final (if the sound ends a word and is preceeded by a vowel sound, excluding blends such as rest and think). Each sound element will be indicated by using dashes to note its position in a word (Wellman, 1931). For example, the sound element initial $[t]$, as in "table," will be indicated by placing the dash after the letter $(t-)$. The sound element medial $[t]$, as in "potato," will be noted by placing dashes on either side of the letter $(-t-)$. Use of the sound element final $[t]$, as in "coat," will be noted by placing 
the dash before the letter $(-t)$.

\section{Substitution}

Substitution will be defined as the use of a different sound element in place of one of the sound elements of either the phoneme $/ t /$ or the phoneme $/ k /$. Substitution will constitute a deviation from correct production, and will be noted by listing the substitute sound element over the sound element which should be used $(x / y)$. 
CHAPTER II

\section{REVIEW OF THE IITERATURE}

The primary concern of the present investigation is to determine at what ages children master the phonemes / $t /$ and /k/. To accomplish this task, it is necessary in this chapter to: 1) review the design and findings of three studies which have examined the development of speech sounds in American English speaking children; 2) compare the results of these studies relative to the ages of mastery for phonemes /t/ and /k/ with statements made by Menyuk (1972) regarding the development of these same phonemes; and 3) review literature dealing with two aspects of traditional articulation assessment: the concept of medial position and imitative vs. spontaneous testing. These last two variables are reviewed in relation to the possible effects they might have had on the results of the three developmental studies mentioned above.

A secondary purpose of the present investigation is to utilize an alternative to the concept of mastery in assigning developmental ages to phonemes $/ t /$ and $/ \mathrm{k} /$. Hence, this chapter also will review an article which presents a new point of view relative to the assigning of ages to developing speech sounds 


\section{DEVELOPMENTAL STUDIES}

Information on the chronological development of the use of phonemes $/ t /$ and $/ \mathrm{k} /$ in words (hereafter called instrumental use, as opposed to pre-verbal or non-instrumental use of speech sounds) and on specific ages when these sounds have reached a high level of development (usually called mastery) has come primarily from one type of research study. This type of study, labeled developmental, has at least four characteristics. One, the researcher examines the chronological development of a number of speech sounds as they are used in the language of the culture. Two, subjects are selected for study on the assumption that they represent normally developing children from various backgrounds. Three, the same sounds are studied at different ages in order to determine the progress of development. This is usually accomplished by means of a cross-sectional analysis, in which a different group of children is studied at each age level. Four, study results usually include developmental tables, with various sounds listed in order by the age level when they are correctly produced by most of the children studied.

Two other aspects of speech sound development studies are the subjects of the pre-linguistic study and those of the clinical study. The pre-linguistic study has as its purpose the examination of sounds used in vocalization during the first two years of the child's life (winitz, 1969). Characteristically, the researcher makes an attempt to record all 
sounds uttered by the child. These utterances are then classified, usually by type and frequency. The clinical study, on the other hand, is designed to examine and record the speech sounds most frequently misarticulated by children usually six years of age and older. Since the present study is concerned with the instrumental development of two specific speech sounds, only the developmental studies of speech sound acquisition will be reviewed here. For further information the reader is advised to consult Winitz (1969), who provides concise summaries of the major pre-linguistic and clinical studies.

The three studies most often cited when instrumental development of speech sounds is at issue are those of Wellman et al. (1931), Poole (1934), and Templin (1957). Results of these studies have become the basis for developmental tables of speech sound acquisition, and have been used as normative guides and as reference points for initiating treatment of defective articulation. They are dealt with here because: 1) they all include the phonemes $/ t /$ and $/ \mathrm{k} /$; and 2 ) one or more of these studies are the basis for most statements made in the last forty years regarding the developmental order of $/ t /$ and $/ k /$. These three studies will be examined according to purpose, subjects (age range, selection, controlled variables), sounds examined, type of articulatory measurement used, and results (type of analysis, criteria for sound development, and specific results for phonemes $/ t /$ and $/ \mathrm{k} /$ ). 
The Wellman et al. Study

In 1931, Wellman and others published a study which was significantly different from previous studies of articulatory development in children in that it was the first attempt at examining a large number of children at several age levels. Further, the study was limited to instrumental use of speech sounds, the first large-scale study to be so defined.

Purpose. Wellman and her associates assessed the ability of preschool children to correctly produce speech sounds in words, and utilized the results to establish tentative age norms for development of speech sounds. They also were interested in: 1) developing procedures for effective articulation assessment of preschool children; 2) studying the effects of various factors on articulation development; 3 ) examining articulation ability with regard to other characteristics of the child; and 4) analyzing errors in the preschool child's use of speech sounds.

Subjects. Subjects for this study consisted of 204 children selected from the preschool classes at the Iowa Child Welfare Research Station. The average IQ was 115.9 (Stanford-Binet Intelligence Scale), with a standard deviation of 15.4. The children ranged in age from two to 6 years. They were divided into one year age groups, ". . from six months past a given year to the next year, five months and twenty-nine days (1931, p. 34)." Such a division places the birthday in the center of the distribution. Evidently the only criteria for inclusion in the study was age and the 
child's presence in the preschool classes, although winitz (1969, p. 58) notes that ". - the children were probably drawn from higher socioeconomic levels."

Speech Sounds Examined. Wellman et al examined 133 sound items. This figure included 66 consonant elements (each consonant was tested, if possible, in 3 word positions: initial, medial and final), 48 consonant blends, 15 vowels, and 4 diphthongs. The phonemes $/ t /$ and $/ k /$ were examined in the consonant analysis. For purposes of sound analysis, the subjects were divided into three groups. Group A included all children and all test sounds (133), although all children were not tested on all sounds. That is, several test words were not produced by some children; therefore, those specific sounds were listed as not tested. Group B included 120 children who were tested on 123 sounds (ten sounds were omitted, again because the desired response words were not produced). Once again, not all 120 children were tested on all 123 sounds. Group C included 57 children who were tested completely on 123 sounds. Since group A included the largest number of subjects, this group will be examined as to their performance on $/ t /$ and $/ \mathrm{k} /$. Out of 204 children, 202 were tested on initial [t], 204 on medial [t], 200 on final [t], 203 on initial $[k], 202$ on medial $[\mathrm{k}]$, and 201 on final $[\mathrm{k}]$. Group $A$ also was used by Wellman and her associates to establish norms. Articulation Test. The method first used by Wellman and her associates to assess articulatory development consisted 
of presenting toys to the child and asking eliciting questions. For the main investigation, however, pictures were substituted for objects due to the fact that toys usually resulted in a longer examination time, more manipulation and playing activity, and less response to eliciting questions. The examiner's task was to present each picture to the child and ask specific eliciting questions. The pictures were selected to produce a number of single word responses, each response containing a specifically desired sound element. For example, picture number one depicted a baby asleep in a baby carriage. Desired responses included "baby, buggy, sleeping," and "wheels." According to Wellman and her associates, the test was designed so that the desired responses were not contained in the eliciting questions. The test situation was not rigidly structured. If a specific sound was not elicited during one test session, an attempt at eliciting was made in later sessions. Each interview lasted from six to 10 minutes, with a complete sound inventory taking from fourteen to 80 minutes, depending on the age of the child and the number and type of responses given to eliciting pictures and questions. For many of the sound units, more than one example was elicited, allowing consistency of articulation to be measured. Some examples of pictures and eliciting questions for measuring the status of instrumental articulation of $/ t /$ and $/ \mathrm{k} /$ are listed below. To test initial and final $\angle \mathrm{kJ}$ and initial $[\forall\rangle$, among other sound elements, the child was presented with one picture depicting a duck, an egg, a kite, a cow, a goat, and a 
hat. Desired responses included "duck, kite, cow, hat," and "goat." The stimulus was "Tell me what all these are." To elicit initial $[\xi]$, the child was shown a picture of two tubs and asked to identify the pictured objects. For medial $[t]$, the picture depicted two dolls. The child was asked, "Is that (pointing) a pretty doll or an ugly doll?" The desired response was "pretty." Apparently this is an exception to the authors' statement that response words were not included in the stimulus. At least one other modeled response was noted, in the phrase "this one or that one (where the desired response was (that')." To elicit medial $[k]$, the child was shown a picture of cookies in a dish, and asked to identify the objects in the dish. The desired response was "cookies." Results. The articulation inventory results were analyzed according to the following variables: age; sex; degree of difficulty of specific sounds and sound groups (consonant elements, consonant blends, vowels, and diphthongs); position of the sound in a word, types of errors, interrelationships among sounds, and relation of articulatory ability to other traits (mental age; introversion-extroversion; vocabulary size; physical size; nutritional status; motor ability; and family size).

In order to discuss difficulty of specific sound elements in relation to age, Wellman and her associates noted the age at which 75 per cent of the children correctly produced the consonant element, blend, vowel, or diphthong. These 
sound-age groupings were described by the authors as "tentative norms" for sound development (1931, p. 49); the information was taken from results of Group A's performance. Results specific to $/ t /$ and $/ k /$ are as follows: At 2 years, 75 per cent of the children correctly used initial $[t]$ in words. At 3 years, correct instrumental use was noted for initial $[t]$, final $[t]$, initial $[\mathrm{K}]$, and medial $[\mathrm{k}]$. At 4 years, initial and final $[t]$, and initial, medial, and final LE] were used correctly. At 5 years, both phonemes ( 6 elements) met criteria. If we consider age of phoneme development to be equivalent to age of development of the last of the 3 sound elements (not necessarily the sound in the final position), then phoneme $/ \mathrm{k} /$ meets criteria at age 4 , and phoneme $/ t /$ at age 5. The sound element medial $[t]$ is the last element of / $t /$ to be acquired. Similar results were encountered by Templin (1957) and Poole (1934) as they examined their data. More will be said about the medial position in a later section.

One further aspect of the results of Wellman and her associates specific to $/ t /$ and $/ \mathrm{k} /$ again should be noted. In several cases, the percentage of correct production dropped from one age to the next. For example, at 4 years of age, 90 per cent of the children tested produced final $[t]$ correctly, while at 5 years this figure dropped to 86 per cent. The sound element final $[\mathrm{k}]$ was correctly produced by 97 per cent of all subjects at 5 years; at 6 years, however, correct production had decreased to 88 per cent. In one instance, correct 
production of the medial $[\xi]$ fell below criteria as the ages of the subjects increased: from 81 per cent at 5 years to 55 per cent at 6 years.

\section{The Poole Study}

Poole (1934) examined the articulatory development of children in a study which followed many of the subjects over a three year period. The study sought to ascertain: 1) the developmental status of various speech sounds; 2) the frequency of occurrence of consonants used instrumentally by preschool children; and 3) the relationship between the developmental order of speech sounds and the factors of audition, kinesthetic sensory discrimination, motor exercise, and dentition.

Subjects. The subjects for the study consisted of 140 children from 2.5 to 8.5 years of age. All subjects were enrolled at the University of Michigan's University Elementary School (nursery, kindergarten, and primary grades one through three). Sixty-five per cent of the school population consisted of children whose parents were staff or faculty members of the University or the University Hospital. School policy permitted enrollment of only those children with "normal mental capacity (not defined)," and required that an annual fee be paid. Poole noted that these factors probably limited her sample to children from relatively high socioeconomic backgrounds. The children were studied over a period of three years, from 1931 through 1933. For approximately one third 
of the subjects, three repititions of the articulation test were administered each year for 3 years; for all children studied, at least one articulation test was administered over the 3 year period. To assess development of instrumental articulation ability, all children were examined at 11 sixmonth age groups.

Speech Sounds Examined. Poole studied the instrumental development of 23 consonants, including $/ t /$ and $/ k /$. When possible, each sound was examined in the customary 3 positions ( $I, M, F)$, resulting in a total of 62 sound elements which might be subjected to analysis. Blends, vowels, and diphthongs were excluded.

Articulation Test. Poole assessed articulatory development by using objects, pictures, and eliciting questions. Part I of the test required the child to draw objects out of a box and name each one as he picked it up. Next, the child was shown a series of pictures, each one depicting certain actions. His task was to respond to examiner questions by describing the actions in the pictures. When responses to the first set of questions had been elicited, questions not related specifically to the depicted action were asked. For example, in reference to a picture depicting a mother picking up her infant son, the question "What color is the baby's shoe?" might be asked. Each object and picture was selected to elicit a word or words containing specific sound elements. In all, forty-two objects and 6 pictures were used. Poole notes that enough objects and pictures were available so that 
each sound element was tested at least twice. Like the procedure used by wellman and her associates, this arrangement allowed consistency of articulation to be measured. If at any time the child did not respond to a specific stimulus, the word was modeled for him, and he was asked to repeat it. For the phoneme / $t /$, specific desired responses were: (initial) "tub, towel, toe, teeth, tape;" (medial) "button, little;" and (final) "velvet, elephant, that." Desired responses for the phoneme / $k$ / were: (initial) "cup, comb, card, cow;" (medial) "chicken;" and (final) "fork, block." Total test time was approximately twelve to fifteen minutes for nursery school children, with test administration taking less than half that time for children in grades one through three. Results. Articulation results were analyzed according to chronological and mental age, a rating of the child's social behavior, length of stay at the University school, reading ability, rate of speaking, sex, and frequency of sound usage. For some of these factors, Poole used only a certain percentage of the subjects. The relation of reading ability to articulation is an example, since only those children in grades one through three had the ability to read. In addition, Poole presented several growth profiles on the articulation development of children who were closely followed for ten or more months. In discussing age and articulation results, poole notes: ". . when the mean (error) score for any sound approaches zero, the sound is considered to be established in the articulation habits of children of that age 
(1934, p. 29)." In other words, a criterion of 100 per cent correct production in an age group had to be met before a sound could be considered learned by children of that age. Unlike Wellman et al., who reported developmental ages for specific sound elements, and let the reader convert the data into ages for phoneme development, Poole reports developmental ages for phonemes, requiring the reader to consult tables within the text for specific sound element ages. Thus, Poole notes that both phonemes $/ t /$ and $/ k /$ were correctly produced by 100 per cent of the children at 4.5 years of age. In consulting the developmental tables, specific results were as follows: final $[t]$ was correctly produced by all children in the 3 year age group; initial [ $\mathrm{t}]$ met criteria at 3 years; and medial $[E]$ was mastered by all children in the 4.5 age group. The first age group in which no errors were made on either initial, medial, or final $[\exists]$ was the group including children ages 4.5 to 5 . The initial sound element of the phoneme /k/ was first produced correctly by all children in the 4 to 4.5 age group. Production of both medial and final [k] met criteria at 3.5 years. The first age group in which no errors were reported on initial, medial or final $[\mathrm{k}]$ was the group including children 4.5 to 5 . We noted earlier in the Wellman et al. study subjects several times decreased in percentage of correct production of a specific sound element as their ages increased. Only once, however, did the production of a sound element drop below criteria after it had been reported as mastered. In Poole's study, because of the strict require- 
ments (100 per cent correct production), any errors would crop the percentage below criteria. For all sound elements, except final $[t]$ and initial $[k]$, errors occurred at ages beyond the age when the sound was correctly produced by all subjects in the age group. Production of the "complete" phonemes $/ t /$ and $/ k /$ also dropped below criteria after the respective sound was reported as developed.

poole's analysis of results, like that of Wellman and her associates, included an examination of the type of articulation errors commonly made by children studied. Poole, however, included data on specific sounds omitted, distorted, or substituted. It is interesting to note that the two phonemes under consideration here are used as substitutes, one for the other, to the exclusion of all other sounds. In children ages 31 to 60 months, the only sound substituted for / $t /$ in all positions was $/ \mathrm{k} /$; a total of 6 substitutions were noted. In the same age range, the only sound substituted for /k/ was /t/; 15 such substitutions were recorded (Poole, 1934).

The Templin Study

Templin (1957) published results of a study dealing with children's developing abilities in four areas of language, including: articulation, sound discrimination, sentence structure, and vocabulary. Here, we are concerned with that portion of the study which examined the development of articulation in the children selected for the project, and specifically, their development of the phonemes $/ t /$ and $/ k /$. 
Purpose. The study was designed to objectively describe children's development in the four language areas. In addition, Templin proposed to analyze the development of each language skill under study in relation to the others. An implied purpose was the collection of normative data on language acquisition.

Subjects. Four-hundred-eighty children, ranging in age from three to 8 years, were selected as subjects. Because measurement procedures for the various language skills were not all appropriate for testing children at 2.5 years of age, children at this age level were not included in the study (a conclusion reached after a number of 2.5 year old children had been tested). Subjects were selected from nursery schools in the Minneapolis-st. Paul area, the Minneapolis public schools (kindergarten and elementary), and from welfare Office surveys. A small percentage of the younger children were tested in their homes, with the rest examined at their school or nursery. Once selection was completed, steps were taken to collect IQ's or IQ equivalents for each subject. Intelligence in children five years and older was measured through administration of the Stanford-Binet Intelligence Scale (already available on most of the children 6 years and older). For the younger children, the Ammons and Ammons Full-Range Picture Vocabulary Test was used to produce an IQ equivalent. Templin reported two children out of 480 with IQ scores (Ammons and Ammons equivalents) under 80 . Since both children responded to all language tests, they were not excluded from the study. No 
mention is made of the techniques used to evaluate the subjects' hearing acuity; it is implied, however, that audiometric screening was not utilized. The total sample of children was selected according to the father's occupation so as to be representative of the United States 1940 Census. Each occupation was classified according to the Minnesota Occupational Scale. A specific number of children were selected at each of six socioeconomic status (SES) levels, resulting in two SES groups: upper (including 30 per cent of the sample), and-lower ( 70 per cent of the sample). These same percentages were maintained in each age group. Subjects were first selected according to age and sex, and then divided into 8 age groups, consisting of children at three, 3.5, four, 4.5, five, 6 , seven, and 8 years. The early half-year intervals were selected since more rapid maturation was expected at these age levels. Each sub-sample was a separate group, including children with ages ranging from one month below the group age to one month above. The total sample included 240 boys and 240 girls, with 30 children of each sex at each age level (a total of 60 ).

Speech Sounds Examined. Templin examined the instrumental use of 176 sound elements: 69 consonants in the initial, medial, and final positions, 71 double-consonant blends, 19 triple-consonant blends, 12 vowels, and 5 diphthongs (Templin, 1957, p. 11). The consonants examined included / $t /$ and $/ \mathrm{k} /$.

Articulation Test. Templin used two word lists for 
articulation assessment, one for children ages six to 8 years, and one for children three to 5. The task of children in the older group was to read the word, or repeat it after the examiner. Children in the younger group either repeated the word after the examiner, or gave a verbal response to pictures. Two word lists were used in order to include some sound discrimination items with the preschool articulation test, thus decreasing administration time. Each word, whether imitated, read, or produced in response to pictures, was selected to elicit a specific test unit (consonant, double and triple blends, vowel, or diphthong). Templin cites a previous study (Templin, 1947) as validation for using either imitation or spontaneous responses to collect articulation data without fear that results would differ significantly with the method used. Since questions have arisen regarding possible effects of the method used to elicit articulation responses, and since the issue is important to the present study, this topic will be discussed in more detail in a later section. For phonemes $/ t /$ and $/ \mathrm{k} /$, the following test words (repeated, read, or pictorially elicited) were used by Templin: initial [t], "toes, table;" medial [ $[\overline{\text { ] }}$, "skating, outing;" final [t], "bat, skate;" initial $\mathrm{MJ}$, "cards, conduct;" medial [kJ, "vacuum cleaner, acorn;" final [kJ, "rake, truck." Administration time of the test was not listed, since it was one part of the four-part language battery. Results. Templin analyzed the results of the articulation test by examining the relationship between articula- 
tory performance and age, sex, SES, and, indirectly, intelligence. Articulatory performance was specified as incorporating total articulation score including: score on consonant elements, blends, vowels, and diphthongs; performance as to sound type (nasals, plosives, fricatives, combinations, and semi-vowels); performance as to position of consonant sound; performance on voiced and voiceless consonants; articulation errors; and development of specific sounds. Here we are primarily concerned with the ages at which specific sounds (/t/ and $/ \mathrm{k} /$ ) are considered developed. These levels of development, which are often cited in the literature as norms, were established by listing the age at which the sound was first produced correctly by 75 per cent of the subjects. In comparing her findings with those of the other studies, Templin lists developmental ages for phonemes, as well as for specific sound elements of those phonemes. For phonemes $/ t /$ and $/ \mathrm{k} /$, Templin reported the following results: the phoneme $/ t /$ met criteria at six years (initial [t], 3 years; medial [t], 6 years; and final $[\xi], 3$ years), while $/ \mathrm{k} /$ was reported mastered at four years (initial and medial $[\mathrm{k}], 3$ years and final $[k], 4$ years). Templin's results, like those of Wellman (1931) and Poole (1934), indicate that percentage of correct production does not automatically increase with age once criteria has been met. In only one instance (final [ [] ), however, did Templin report a sound element meeting criteria at one age level and then falling below at later ages. Wellman et al. (1931) reported similar findings for medial $[\xi]$, while 
Poole's results (1934) indicated that four of 6 sound elements of phonemes / $t /$ and $/ \mathrm{k} /$ met criteria and later dropped below.

\section{RESULTS OF THE THREE DEVELOPNENTAL STUDIES COMPARED WITH MENYUK'S HYPOTHESES \\ RELATIVE TO PHONEMES / $t /$ AND / $k$ /}

With the above studies examined as they relate to the development of the phonemes $/ t /$ and $/ k /$, Menyuk's argument (1972), presented in Chapter I, can be studied more extensively. Upon examination, two observations are made: 1) the phoneme $/ t /$ must develop before the phoneme $/ \mathrm{k} /$, since $/ t /$ is theorized to be a necessary prerequisite to $/ \mathrm{k} /$; and 2 ) in $\mathrm{A}-$ merican English, the initial sound element of the phoneme / $t /$ is mastered at an earlier age than initial $[\mathrm{k}]$. Menyuk's source for her hypotheses regarding the phonemes / $t /$ and $/ k /$ was Powers (1957), who summarized in tabular form four "investigations" related to the instrumental development of speech sounds (see Table 1). Of the four, the wellman et al. study (1931) and the research done by Poole (1934) were the only two providing original information on ages for purposeful use of specific speech sounds. The Templin "study" (1952) was a description of the initial results and ongoing analysis of the study published in 1957. As can be seen from Table 1, Templin's 1952 report listed ages at which a high percentage of the subjects correctly used sound types in words, and hence does not provide information on ages for development of specific sound elements. The findings attributed to Roe (1950) are rather confusing. In the original text, Roe cites no source 
TABLE 1

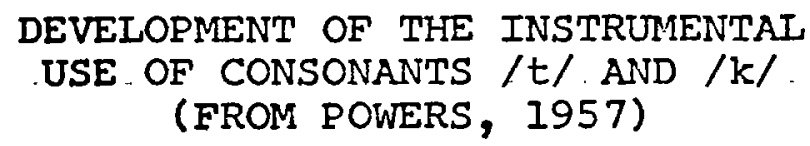

\begin{tabular}{|c|c|c|c|c|}
\hline Age & \multicolumn{4}{|c|}{ Investigator } \\
\hline & $\begin{array}{l}\text { Wellman et al. } \\
\text { (I93I) }\end{array}$ & $\begin{array}{l}\text { Poole } \\
(1934)\end{array}$ & $\begin{array}{l}\text { Roe } \\
(1950)\end{array}$ & $\begin{array}{l}\text { Templin: percentage } \\
\text { of correct produc- } \\
\text { tion (1952) }\end{array}$ \\
\hline 2 & $\angle t=]$ & & & \\
\hline 2.5 & & & & \\
\hline 3 & $\begin{array}{c}{[-\mathrm{t}] \quad[\mathrm{k}-]} \\
{[-\mathrm{k}-]}\end{array}$ & & & $\begin{array}{l}66 \text { per cent of } \\
\text { consonants }\end{array}$ \\
\hline 3.5 & & & & \\
\hline 4 & {$[-\mathrm{k}]$} & & $\begin{array}{l}\mid t / \\
|k|\end{array}$ & $\begin{array}{l}80 \text { per cent of } \\
\text { consonants }\end{array}$ \\
\hline 4.5 & & $\begin{array}{l}/ \mathrm{t} / \\
/ \mathrm{k} /\end{array}$ & & \\
\hline 5 & $E t=]$ & & & \\
\hline 5.5 & & & & \\
\hline 6 & & & & $\begin{array}{l}90 \text { percent of } \\
\text { consonants }\end{array}$ \\
\hline 7 & & & & $\begin{array}{l}90 \text { per cent of } \\
\text { consonants }\end{array}$ \\
\hline
\end{tabular}


for the data, which is found under a heading entitled "The Usual Ages for Mastery of Sounds (1950, p. 78)." The Wellman et al. study (1931), however, is included in the reference list at the end of the article.

As listed by Powers, the findings of Roe, Poole and Templin do not divide phonemes into individual sound elements, indicating that Menyuk used only the Wellman et al. study (1931) as a basis for stating that initial [t] develops prior to initial $\angle \mathrm{kJ}$. The findings of wellman and her associates, reported by Powers (Table 1) and summarized in a previous section do indicate that initial $\angle \Theta J$ is mastered before initial $[k]: \angle E=7$ at age two, and $[K=]$ at age 3. This information, from one study only, corresponds to Menyuk's hypothesis. One wonders why Menyuk apparently did not consult the Templin study (1957) reviewed above. As we have seen, Templin's findings relative to phonemes $/ t /$ and $/ \mathrm{k} /$ indicate that both sound elements initial $[€]$ and initial $[K \bar{J}$ are mastered at age 3. Based upon Powers' article, Menyuk's hypothesis that initial $[E]$ is mastered before initial [K], appears reasonable. The additional information supplied by Templin (1957), however, indicates the need for further study before a definitive statement regarding order of development of sound elements initial $[\mathrm{E}]$ and $[k]$ can be made. The present study is an attempt to contribute such information. Menyuk also discusses the order of development of the two phonemes, each including 3 sound elements. The implication is that the phoneme $/ \mathrm{k} /$ cannot be acquired before phoneme 
/t/. Table 2, prepared from results of the 3 major studies, summarizes ages when the two phonemes are said to be learned by children. As can be seen, the Wellman and Templin findings indicate that phoneme $/ \mathrm{k} /$ is mastered at least one year earlier than phoneme $/ t /$. Thus, Menyuk's hypothesis regarding development of phonemes $/ t /$ and $/ k /$ appears also to require further clarification, again a purpose of the present study.

\section{TRADITIONAL ARTICULATION ASSESSMENT}

\section{Medial Position}

The concept of "medial position" is important to this study and to the initial question. Menyuk (1972) has implied that the phoneme $/ t /$ develops before the phoneme $/ \mathrm{k} /$. As has been seen, the data of Wellman et al. (1931) and Templin (1957) do not support this claim (Table 2). An important point, however, must be made. As defined by the designs of the three studies, "phoneme" is one sound tested in 3 positions within a word: initial, medial, and final. It was noted earlier that in all three studies, the sound element medial $[t]$ was the last to be mastered. The results of Templin and Wellman et al. indicating that the phoneme $/ \mathrm{k} /$ develops before the phoneme / $t /$, would be markedly different if the medial elements were not included. Templin's findings, excluding the medial elements, indicate that phoneme / $t /$ is mastered at age 3 , while phoneme $/ \mathrm{k} /$ is mastered at age 4 . Without the medial elements, the results of Wellman and her associates are the same as those of Templin: / $t /$ at age 3 , and $/ \mathrm{k} /$ at 
TABLE 2

COMPARISON OF THE AGES AT WHICH SUBJECTS

IN THE THREE DEVELOPMENTAL STUDIES

MASTERED / $t /$ AND / $/ \mathrm{k}$ :

SOUND ELEMENTS AND

PHONEMES

\begin{tabular}{|c|c|c|c|}
\hline Sound Element & \multicolumn{3}{|c|}{ Investigator } \\
\hline & $\begin{array}{c}\text { Wellman et al. } \\
(1931)\end{array}$ & $\begin{array}{l}\text { Poole } \\
(1934) \\
\end{array}$ & $\begin{array}{c}\text { Templin } \\
(1957)\end{array}$ \\
\hline$\langle t-\rangle$ & 2 years & 3 years & 3 years \\
\hline$[-t-]$ & 5 years & 4.5 years & 6 years \\
\hline$[-t]$ & 3 years & 3 years & 3 years \\
\hline$\angle k=7$ & 3 years & 4 years & 3 years \\
\hline$\angle-k=7$ & 3 years & 3.5 years & 3 years \\
\hline$[-\mathrm{k}]$ & 4 years & 3.5 years & 4 years \\
\hline Phonemes & & & \\
\hline$/ t \mid$ & 5 years & 4.5 years & 6 years \\
\hline$/ k /$ & 4 years & 4.5 years & 4 years \\
\hline
\end{tabular}


age 4. The findings of Poole indicate that both $/ t /$ and $/ k /$ are mastered at 4.5 years. Omit the medial elements, howev$e r$, and the age for $/ t /$ drops to 3.5 years, while remaining at 4.5 years for $/ \mathrm{k} /$ (Table 3 ). In other words, when both medial $[\underline{\xi}]$ and $[k]$ are omitted from the age-assigning process for the two phonemes, results indicate that the phoneme $/ t /$ is mastered at an earlier age level.

To determine why the sound element medial $[t]$ was the last to be "learned" by children in all three studies, it will be helpful to examine some of the words used to elicit the sound element in question. Wellman et al. (1931) used the word "pretty," among others, to elicit medial [€]. Poole (1934) selected "button" and "little" for the same purpose. Words used by Templin (1957) to elicit medial $[t]$ included "skating" and "outing." One can assume that the words were selected because it was felt, when uttered, they would "produce" a voiceless, lingua-alveolar stop $(/ t /)$ somewhere between the initial and final consonants. They also may have been selected because some were easily represented with pictures. As will be seen, however, they were apparently chosen without regard for the phonetic environment of medial $[\exists]$, a point amplified by Keenan (1961). When commonly pronounced, the words "skating, outing," and "pretty," as well as similar words, tend to produce a sound approaching a voiced / $t$ / (Templin, 1957, 1973; and Sander, 1972). In the words "button" and "little," the syllabic environment is such that the medial $\angle E$ is usually not released, in order 
TABIE 3

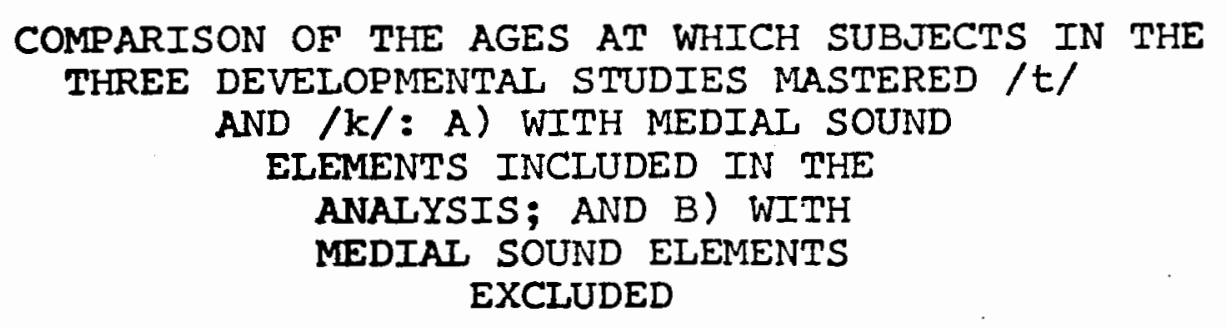

\begin{tabular}{|c|c|c|c|}
\hline Phonemes & \multicolumn{3}{|c|}{ Investigator } \\
\hline & $\begin{array}{c}\text { Wellman et al. } \\
(1931)\end{array}$ & $\begin{array}{l}\text { Poole } \\
(1934)\end{array}$ & $\begin{array}{l}\text { Templin } \\
(1957)\end{array}$ \\
\hline $\mid t /(A)$ & 5 years & 4.5 years & 6 years \\
\hline$/ t /(B)$ & 3 years & 3.5 years & 3 years \\
\hline$/ k /(A)$ & 4 years & 4.5 years & 4 years \\
\hline$/ k /(B)$ & 4 years & 4.5 years & 4 years \\
\hline
\end{tabular}


that the tongue may rapidly move to the position for the $/ n /$ or $/ I /$ phoneme. Although discussing the phoneme /d/ in "garden," Keenan's comments (1961) are applicable also to the phoneme / $t /$ as found in "button" and "little." Keenan notes that in the common pronunciation of "garden," the /d/ ". . is an inextricable part of the syllable gestalt and might best be transcribed as $[\mathrm{d} 7$. - (1961, p. 171)." Thus, the characteristics of $/ t /$ (a voiceless lingua-alveolar stop) are muted by the phonetic environments in the examples noted above.

With the above information regarding the words used to elicit medial $[t]$ in the three developmental studies, an explanation for the later age of development for sound element medial $[t]$ can be hypothesized. The phonetic environment of the target sound [ $t-]$ results in that sound losing one or more of its characteristics, thus creating difficulty for the listener or examiner, who presumably is listening for a /t/ with acoustic properties similar to the sounds in such words as "table (initial)" and "coat (final)." The point of interest is not that the sound element medial $[t]$ has been assigned a developmental age later than the other sound elements of $/ t /$, but that it was assigned any age at all. In order for a high percentage of children to "correctly" produce the sound element medial $\measuredangle t\rceil$ in words like "skating, outing, pretty, button," or "little," it would appear that the listener would have to have a "judgement set" specific to medial [t]. Said in another fashion, the words used do 
not seem to produce a clear example of the phoneme / $t /$ in the medial position, thus, requiring perhaps a change in criteria in order that "correct production" might be obtained by the required percentage of children. In this regard, it is interesting to note that in the developmental investigations cited above, one listener in each study made all judgements regarding sound development. It would seem a difficult task indeed for a panel of listeners to arrive at any sort of agreement regarding the presence or absence of medial $[\mathrm{Z}$ ] in the above words, unless the judges were given a specific set of listening instructions.

An important realization to be gained from the preceding discussion is that the term "medial position" has been used to refer to phonemes in a variety of phonetic contexts, under the implied assumption that the same sound was being examined in the same fashion in each study. Keenan (1961) refers to a list of words commonly used to elicit medial [d]. In each word, the target sound varies in phonetic context, in syllabic position, or syllabic stress. For example, the sound might occur as the initial phoneme in an unstressed syllable, as in the word "candy," or as the initial phoneme in a stressed syllable, in the word "today." The word "admire" results in the sound element occurring as the terminating consonant in an unstressed syllable, while common production of "woodpecker" causes $/ d /$ to occur as the terminating consonant in a stressed syllable. Keenan's solution to the confusion caused by use of the term "medial" is to re- 
classify consonants according to: 1) their relationship to the syllable and 2) their position regarciing word or phrase. Consonants beginning or ending a word or phrase are classified as external, while those spoken within a word or phrase are labeled internal. Whether internal or external, consonants are classified as prevocalic if they initiate a syllable, and postvocalic if they terminate a syllable. A further classification for internal consonants is "intervocalic." An example of this classification occurrs in the words used by Templin and Wellman et al. to elicit medial [t]: "skating, outing," and "pretty." In this case, the phoneme / $t$ / ". . cannot be unequivocably placed with either the preceding or the following vowel (Keenan, 1961, p. 173)." In the three developmental studies examined, we have seen examples of the term "medial" being used to refer to consonants located in at least two different phonetic environments. Results of childrens' productions of $/ t /$ in these dissimilar environments, however, are classified and compared under the one term "medial."

Two conclusions can be reached from the discussion of medial position. First, the later age when medial $\measuredangle \forall$ is reported as learned (in the three developmental studies) may relate not to any inherent difficulty involved in producing phoneme / $t /$ in the middle of a word, but to the word selected to elicit the target sound, and to the effects of that word on the target phoneme and its acoustic result which reaches the ear of the listener. Second, and more 
basic is the use of the term itself. As has been noted, "medial [ $t]$ " has at least two operational definitions, depending on the study (Wellman et al., Poole, or Templin) examined.

Templin (1973) has indicated that a solution to the problem posed by medial position is to drop the concept from the definition of phoneme, as used in articulation assessment. An example of this type of thought is the revised version of the Templin-Darley Tests of Articulation, which does not include medial position in assessing the development of most phonemes, including $/ t /$ and $/ k /$ (Templin and Darley, 1969). In addition, the instrument devised by Irwin and Musselman (1962) does not contain sound elements in the medial position.

Imitative Versus Spontaneous Testing

There is another question which has arisen concerning the methodology used in the three developmental studies (Wellman et al., 1931; Poole, 1934; Templin, 1957) and the resulting validity of ages assigned to developing sounds. At issue is the method of eliciting the test word, and the possible effects of that method on the results.

Two types of procedures have been traditionally used in articulation assessment to elicit a response. From its label, the "spontaneous" method would seem to indicate that samples of a child's non-directed conversation are recorded and later analyzed to determine if the target sound was produced. Although this method has been used, its limitations 
have prevented its widespread use, especially where evaluation time must be kept at a minimum. As commonly used, the spontaneous method is simply a method of eliciting a target word without supplying an auditory model of that word to the child (Irwin, 1972). Wellman et al. (1931), Poole (1934), and Templin (1957) used a spontaneous method to elicit the target sounds. Pictures or objects were presented to subjects with the instructions that the items be named. The pictures and objects to be named were selected so that the resulting word, when verbally identified, would produce an example of the target sound. Eliciting a sample by having a child read a list of pre-determined. words also can be considered a spontaneous method. The method, however, is useless when the articulation development of preschool children is being assessed, since most of these children, if not all, are unable to read.

The second method used to elicit response in articulation testing is referred to as the imitation, or imitative method. The examiner utters the pre-chosen target word or phrase, then has the subject repeat back the test unit. As with the spontaneous method, the words used are chosen so that their production will result in the utterance of the target sound in various contexts. Poole (1934) and Templin (1957) used the imitative method as an alternative when objects or pictures failed to elicit the sound. As has been previously mentioned, the Wellman et al. study was designed to use only the spontaneous method to elicit responses. If 
a word could not be elicited during the picture-naming sessions, the target sound was listed as not tested (Wellman et al., 1931). At least one example occurred in this study, however, where subjects were presented with an auditory model as well as a picture, thus, resulting in both acoustic and visual clues.

The controversy regarding the method used to elicit target sounds stems from some evidence presented below which indicates that children who reproduce modeled words (imitative method) will achieve better results (higher score or earlier assigning of a developmental age) than those children who respond to pictures or objects. Thus, normative ages for specific speech sounds have been questioned if they resulted from studies where some sounds or sound elements were elicited by providing an acoustic model for the child. The studies of Poole (1934), Templin (1957) and, to a small extent, the wellman et al. study (1931) all produced results within this classification.

Evidence that the imitative method tends to produce better articulation scores has come from the work of snow and Milisen (1954), Carter and Buck (1958), and Smith and Ainsworth (1967). These studies examined articulatory-defective children ages six and older. In addition, Siegal and others (1963) produced results similar to the above siudies. Their population consisted of kindergarten children unselected with regard to articulation problems. On the other hand, Templin (1947), provides some evidence that 
articulation performance does not differ significantly with the test method used. Templin's subjects were preschool children ages two to 6 , who were not selected according to articulation ability.

One further study will be mentioned regarding method of stimulus presentation. Kresheck and Socolofsky (1972) provide evidence which suggests that normal four-year old children perform significantly better on an articulation test when the imitative method of stimulus presentation is used as opposed to the spontaneous method. Forty-five 4 year old children, selected at random from Chicago area preschools, were presented with 87 words from the Templin-Darley Tests of Articulation (1969). Each child was first tested using a spontaneous method, followed within one week be the same words presented with the imitative method. Results indicated a significant difference in articulation scores between the two methods, with the difference favoring the imitative procedure. It is interesting to note the effects on production of $/ t /$ and $/ k /$ as a result of the method of stimulus presentation utilized. Three words were used to elicit the target sound elements for $/ \mathrm{k} /$ : "cat (initial)," "pockets (medial)," and "truck (Einal)." Forty-five correct responses (from 45 subjects) were obtained on each sound element regardless of the method used. The phoneme / $t /$ was tested in two positions (initial and final). Words used were "two (initial)" and "boat (final)." Fortyfive subjects correctly produced initial $[t]$ when the spon- 
taneous method was used, while 44 correct responses were recorded with the imitative method. For final $[z], 45$ correct responses were noted with each method of stimulus presentation. Results indicate that in this case production of the $/ \mathrm{k} /$ phoneme was not influenced by modeling. Results also indicate a slight trend toward better production of initial [t] when modeling was provided (Kresheck and Socolofsky, 1972).

The evidence presented above indicates that the imitative method of eliciting target phonemes may provide the subject with enough information regarding the acoustic characteristics of the target that his performance will be better than if the target sound were elicited spontaneousiy. Kresheck and Socolofsky (1972) indicate that this tendency also may exist when testing normally developing four year old children. Previously, as seen above, most information regarding the effects of the imitative method had come from school-age articulatory defective children. Because the Poole (1934) and Templin (1957) studies used imitation only when the spontaneous method failed to elicit the sound, we must assume that those sounds where imitation was used may have had an assigned developmental age which was artificially lowered. Wellman and her associates, except for isolated instances of including the target word in the eliciting phrases, did not use any method where an acoustic model would be provided (1931). Since we are concerned here with developmental ages for $/ t /$ and $/ k /$, it would be help- 
ful to know if any sound elements of these phonemes were modeled, thereby increasing the possibility that developmental ages were artificially lowered. Unfortunately, neither Templin nor poole provide information as to which sound element had to be modeled.

In any study designed to determine ages of development for specific sounds, the method used to elicit articulatory responses from children should be as efficient and as systematic as possible. If the goal is to determine the level of the child's ability to produce specific sounds, then a method designed to elicit spontaneous utterances should be used as far as possible. Abandoning the study or using an unsystematic, time-consuming "free speech" method to elicit those few sounds with which visual stimuli fail to elicit the target word, however, would seem to be an unnecessary step. A feasible alternative would be some type of "trade-off" or compromise method. It is the Investigator's opinion that target words used in a developmental study should be selected so as to be easily represented by clear, attractive pictures. It is also felt that if this procedure is carefully followed, few sounds would require modeling. When the imitative method is required, each modeled sound could be recorded as such, and noted in any discussion of results. In addition, a procedure suggested by Irwin (1972) where the target word is included in a phrase or sentence, could reduce or perhaps eliminate any effects caused by imitating an isolated word. 


\section{MASTERY: A NEW POINT OF VIEW}

The final issue to be discussed in this chapter concerns the meaning and implications of the term "mastery," as used in reference to a certain level of instrumental speech sound development. As operationally defined by the three developmental studies (Wellman et al., 1931; Poole, 1934; and Templin, 1957), mastery refers to that level of instrumental speech sound development when a high percentage of children at a particular age correctly produce specific phonemes in 3 positions within words. Menyuk (1972) used the term "mastered" when referring to the apparent earlier development of initial $[t]$ as opposed to initial $[k]$.

Sander (1972) notes that the criteria for mastery established by the three developmental studies produces results which reflect age limits, rather than average ages for correct production. To emphasize the arbitrary nature of the traditional definition of mastery, Sander discusses several alternative methods for defining sound development in children. For example, phoneme learning could be determined by requiring the child to correctly produce the sound in consonant blends, as well as in single consonant positions, thus, necessitating correct production in 6 word positions: 3 with a single consonant, and 3 with blends. In its strictest sense, "mastery" might be defined as complete knowledge and correct usage of a phoneme category. The child who correctly produces a consonant sound in every available context 
might not have completely learned to instrumentally use that sound if he is discovered to substitute it incorrectly for another.

Various earlier stages in articulatory development also could be used to assign ages for phoneme development. Sander suggests that the age when a child first produces a phoneme correctly in a word could be used in assessing the level of sound development. The problems of data collection, however, would limit the usefulness of this stage as a normative landmark. Another suggestion is to assign ages to instrumentally developing phonemes ". . at that point when a child is producing a sound correctly more often than he is misarticulating or omitting it (1972, p. 59)." Sander terms this level the age of customary or average production. The phoneme /s/ is used by Sander to illustrate the varieties of criteria which could be used in defining instrumental sound development. According to poole (1934), /s/ is mastered at age 7.5 , while Templin reports mastery for the same phoneme at 4.5 years. The difference probably stems from Poole's demand that all children within an age group (100 per cent) correctly produce a sound before an age level was assigned. Templin's criteria, as noted above, was 75 per cent. Using Templin's data, Sander applies his criteria for average or customary age of mastery (here defined as correct production in each of three word positions by 50 per cent of an age group) to the phoneme /s/, resulting in a developmental age of 3 years. To demonstrate the other ex- 
treme, again with Templin's data, a criteria of correct production in three positions by 90 per cent of children within an age group is used, raising age of mastery for the phoneme /s/ to 8 years. The point is to emphasize the arbitrary nature of age levels established in traditional studies.

Sander's alternative to the concept of mastery is to provide two age levels for each instrumentally developing speech sound. He proposes including both average age of customary production and an age reflecting traditional upper limits in normative schedules of speech sound development. One method of obtaining age of customary production for a specific sound is to use data collected in previous studies (Wellman et al., 1931; Poole, 1934; and Templin, 1957) to determine the age when a speech sound is correctly produced in two out of three word positions by 51 per cent or more of the children in an age group. Sander labels the product of these calculations as ". . the average age of customary consonant articulation (Sander, 1972, p. 60)." For the proposed normative schedule (see Table 4), the definition is modified to include those consonant sounds testable in only two word positions, such as $/ \eta /$. Therefore, ages which correspond to the starting point of the solid bar (Table 4) are determined by adding the percentage figures (number of children correctly producing the sound) for all word positions tested, and then averaging these figures. The earliest age at which the test average at the various word 
TABLE 4

PROPOSED NORMATIVE SCHEDULE FOR THE

DEVELOPMENT OF CONSONANT SOUNDS

(SANDER, 1972)

Age Level

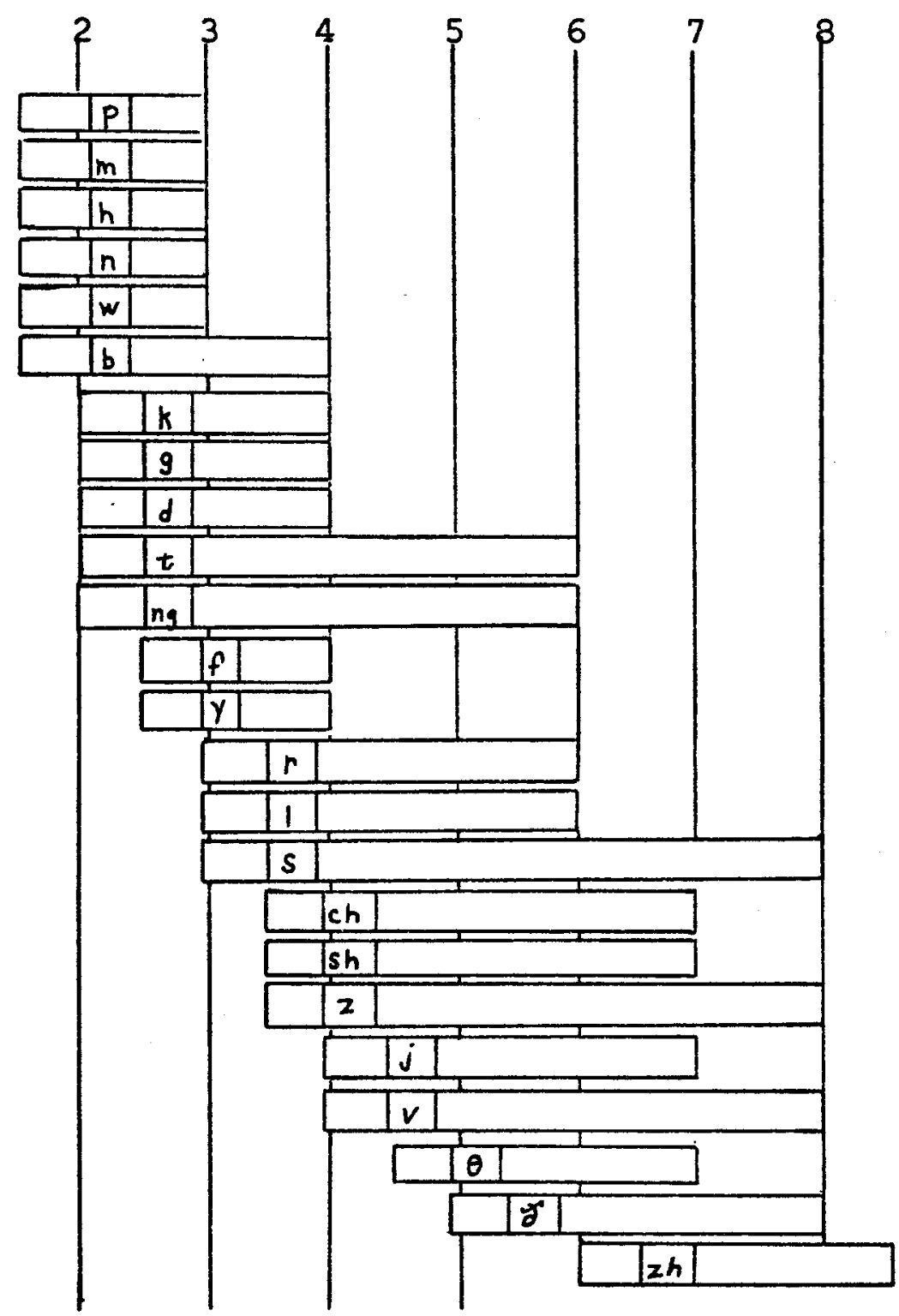


positions is greater than 50 per cent is the average age of customary consonant production. Sander's schedule also includes upper age limits similar to those obtained by the previously mentioned studies. These ages (corresponding to the stopping point of the solid bar) are defined as "upper age limits of customary production (1972, p. 61)." They are obtained in a similar fashion as the ages of average customary production, except in this case the test average at the various word positions must reach 90 per cent before ages are assigned to the sound being examined (Sander, 1972).

Sander's procedure for defining age of customary production might produce methodological difficulties, especially with early developing speech sounds. Since it is felt, however, that more information regarding the early instrumental development of phonemes $/ t /$ and $/ k /$ would be useful, the present study attempts to incorporate sander's concept of age of customary production. For this study, customary production is termed "acquisition."

\section{CHAPTER SUMMARY}

In the preceding chapter, literature was reviewed which pertained to the main topic of the present investigation: the ages of mastery and resulting developmental order of phonemes $/ t /$ and $/ k /$. Three specific aspects of this topic were examined. First, the studies of instrumental speech sound development conducted by wellman et al. (1931), Poole (1934), and Templin (1957) were reviewed. These investiga- 
tions were examined for two reasons: 1) to determine previous methods used to assess the development of speech sounds; and 2) to obtain the developmental ages assigned by the three studies to the phonemes $/ t /$ and $/ k /$. The findings of these three studies relative to $/ \mathrm{t} /$ and $/ \mathrm{k} /$ will be compared with results from the present investigation. Second, two observations by Menyuk (1972) regarding the development of $/ t /$ and $/ k /$ were compared with results of the three developmental studies. Menyuk hypothesized: 1) that the phoneme $/ t /$ is necessary for the development of $/ \mathrm{k} /$; and 2 ) that the sound element initial $[\exists]$ is mastered before initial [k]. The findings of the three early studies were used to point out several inconsistencies between Menyuk's hypotheses and the available data relative to the development of the phonemes $/ t /$ and $/ \mathrm{k} /$. The results of the present investigation also will be compared with Menyuk's observations. Third, two aspects of traditional articulation assessment were reviewed: the concept of "medial position," and imitative vs. spontaneous testing. Both problems were examined in relation to the possible effects they may have had on the findings of the three developmental studies. Literature was presented which detailed the criticism regarding the procedure of testing phoneme development in the medial position. The present investigation will deal with the questionable validity of this concept by presenting two sets of developmental ages for $/ t /$ and $/ k /$; one set will exclude the medial sound elements from analysis. The problems posed by the 
method used to elicit the target sound (imitative vs. spontaneous) were also reviewed. Sources consulted agreed that the imitative method is usuaily necessary to elicit target sounds from some subjects in studies of speech sound development. Evidence also was presented which indicated that the imitative method tends to improve the subject's test performance by providing him with additional auditory information. In light of these data, the present investigation will: 1) attempt to reduce the need for target sounds to be modeled; 2) provide a minimum of auditory cues when a sound must be modeled.

The preceding chapter also was utilized to review literature pertinent to the secondary purpose of the present investigation: the use of an alternative to the concept of mastery in assigning developmental ages to phonemes. The concept of mastery of speech sounds was examined and an alternative method of assessing phoneme development was presented. This method will be utilized in the present investigation. 


\section{CHAPTER III}

\section{METHODS AND PROCEDURES}

\section{SUBJECTS}

Seventy children, including ten in each of 7 six-month age groups, were selected from preschools and day-care centers (both will be henceforth referred to as preschools) in the greater Portland area. The Portland telephone directory was utilized to compile a list of names, addresses, and telephone numbers of preschools in the area. The following general headings, found in the commercial section of the directory, were used to locate agencies where children of the appropriate ages might be found: "Schools," "Day Nurseries," and "Kindergartens." In this fashion 144 preschools were located. Each preschool was assigned a number, and by referring to a table of random numbers, a list of preschools was compiled. As each number was chosen, the agency to which it corresponded was telephoned and asked to cooperate in the study. The first ten preschools which agreed to allow their children to participate were selected for use in the study (see Appendix A). An introductory letter also was sent to each school (see Appendix B).

When ten preschools were selected, all children within these schools between the ages of two and six were screened to 
determine their socioeconomic status (SES). Following completion of this screening procedure, 237 children were available as potential subjects for the study. This sample was divided into age groups, resulting in a sample of 195 children in seven separate groups. Within each age group, children were assigned numbers. Using a random sampling procedure, five males and 3 alternates, and five females and 3 alternates were selected from each age group. Alternate subjects were used if the original child did not respond to one or more of the instruments used in the study. Alternates also were used if the originally selected child was unavailable on the day of testing at a particular preschool.

\section{VARIABLES}

Variables which were controlled in the present study are among those which have been consistently mentioned in the literature as affecting articulation development (Poole, 1934; Templin, 1953; Winitz, 1969; and Irwin, 1972). Of particular interest here were the factors of age, socioeconomic status, intelligence, and auditory acuity.

\section{Age}

The developmental status of phonemes $/ t /$ and $/ k /$ was assessed in children ranging from 2.5 years to 6 years. This relatively wide age span in relation to number of phonemes examined was used to facilitate comparison of results of the present study with those compiled by previous researchers. 
An initial goal of the study was to include children ages two to 2.5 years in the sample population. Of the ten preschools selected, however, only two included children in this age group as enrollees. In addition, while test procedures were generally effective with children ages 2.5 and older, children younger than this age did not respond consistently to any measure. This was especially true regarding the screening of auditory acuity. Consequently, the few children who were testable in the two to 2.5 age category were not included in compiling the total results.

When screening for socioeconomic status was completed, the remaining children from each school were grouped according to age. A conservative estimate of the time required to test all children on all measures was two months, from the first week in October, 1973, through November 30th, 1973. The midpoint of this time period was November 1, 1973. As soon as a subject was located and had passed SES requirements, his birthdate and resulting age on November 1 was recorded. The child's age on the target date (November I, 1973) was utilized as a selecting factor to allow testing to be done before and after this date and still ensure that subjects would be of the appropriate ages. If the child's age on the first day of November was between $x$ years, one month and $x$ years, five months (for the age groups 3, 4, and 5 ), or between $x$ years, seven months and $x$ years eleven months (for age groups $2.5,3.5,4.5$, and 5.5 ), he was included in the sample as meeting age requirements. If the 
child's age as of November $I$ was $x$ years, five months and one day or older (for ages 3,4 , and 5), he was rejected as a subject. For the same age groups 3, 4, and 5, a child was not included if his age on the target date was less than $x$ years and one month (e.g., three years and twenty-nine days). Children were not included in the age groups $2.5,3.5,4.5$, and 5.5 years if their ages on the first of November were less than $\mathrm{x}$ years, seven months or greater than $\mathrm{x}$ years, eleven months. As an aid in determining ages, "month" was defined in the above procedure as including 30 days.

When the children had been initially selected according to age, they were separated according to age groups. The target number in each group was twenty or more children, from which were randomly selected 16 (ten designated as subjects and six as alternates). The actual mean ages of children utilized as subjects in each of the 7 age groups are listed in Table 5.

\section{Socioeconomic status}

A criticism often raised concerning the developmental study done by Wellman et al. (1931) was the high socioeconomic level of the children studied (winitz, 1969). Poole (1934) noted that her subjects were probably drawn from relatively high socioeconomic levels. Templin (1957) attempted to control any effects caused by the child's social and economic environments by studying children at two socioeconomic levels: upper and lower (see Chapter II). Because of the pos- 
TABLE 5

MEAN AGE OF CHILDREN IN

EACH AGE GROUP

\begin{tabular}{|c|c|c|}
\hline $\begin{array}{l}\text { Age } \\
\text { Group }\end{array}$ & $\begin{array}{l}\text { Mean Age in } \\
\text { Years and Months }\end{array}$ & $\begin{array}{l}\text { Mean Age in } \\
\text { Months }\end{array}$ \\
\hline 2.5 to 3 & 2 years, nine months & 33 months \\
\hline 3 to 3.5 & 3 years, three months & 39 months \\
\hline 3.5 to 4 & 3 years, eight months & 44 months \\
\hline 4 to 4.5 & 4 years, three months & 51 months \\
\hline 4.5 to 5 & 4 years, nine months & 57 months \\
\hline 5 to 5.5 & 5 years, three months & 63 months \\
\hline 5.5 to 6 & 5 years, nine months & 69 months \\
\hline
\end{tabular}


sible effects on the findings of Wellman et al. (1931) and Poole (1934) due to the higher SES of the subjects, it was decided to include a screening device in the design of the present study so that some information would be available concerning the social and economic backgrounds of the subjects. The target sample regarding SES was a group of subjects representing all urban American children between, but not including, upper and lower social and economic levels.

For this study, limited by time and resources, "socioeconomic status" was determined by the occupation of the chief income recipient in the child's family. The occupation was assigned a numerical value, found by consulting Working paper Number 15: Methodolooy and Scores of Socioeconomic Status (U.S. Bureau of the Census, 1963). Using this instrument, occupations were assigned values ranging from 01 (low) to 99 (high), depending on skill required, training involved, and indirectly, on income received. In the initial location of candidates for the study, children were tentatively accepted as subjects if the occupation of the chief income recipient in the family fell within a value range of 40 to (and including) 86 on the screening instrument. This range includes the social and economic backgrounds of a majority of the United States population (U.S. Bureau of the Census, 1963). The occupation of the chief income recipient in the child's family was obtained by first consulting the preschool records available for each child. A preschool staff member was usually available to assist in gathering the necessary 
data. In most schools, the initial application form (used to obtain occupational data) required the parent to list employer, rather than occupation. Thus, the specific occupation was discovered by one of 3 methods: 1) the staff member was found to be familiar with the parent and occupation; 2) the occupation was listed by the parent; or 3) the firm or place of business was specific enough to allow the occupation to be deduced. If the parent's place of employment did not seem to relate to a specific activity, the parent occupation was listed as "not stated," with a corresponding point value of 33 (U.S. Bureau of the Census, 1963). In situations where both parents were employed, with occupations listed for both, the father's occupation was arbitrarily selected for analysis. Due to the time and effort involved, parents were not contacted directly regarding occupation, a procedure which also might have affected their involvement in the study.

\section{Intelligence}

Intelligence, based upon the verbal facility of each subject, was screened through the use of the Peabody Picture Vocabulary Test (PPVT), Form A (Dunn, 1965). It is recognized that this instrument may tap only one aspect of "intelligence," i.e., the child's auditory vocabulary. The results of Taylor (1963), however, indicate that the test is useful as a procedure to screen verbal intelligence.

The test was administered as the second item of a 3-part test battery, which included an auditory screening and the 
test to assess the development of $/ t /$ and $/ \mathrm{k} /$. Total evaluation time was approximately thirty minutes for each child. Children who were evaluated in this manner had previously been screened for socioeconomic status and age. All children who achieved a PPVI IQ equivalent of 80 or above, and who were determined to have normal hearing were shown the pictures comprising the articulation test. Two children who received PPVT scores below 80 were excluded from the study. Table 6 lists the mean PPVT IQ equivalents for each age group.

\section{Auditory Acuity}

In order to rule out the possibility of hearing loss and any subsequent contamination of articulation test results, only children with normal hearing were included as subjects. A Beltone model $10 \mathrm{C}$ portable audiometer equipped with Auraldomes (model AR 100) was used to administer a puretone audiometric screening test to all study candidates. The Auraldomes were used in an effort to reduce ambient noise common in most preschool environments. A screening level of $15 \mathrm{~dB}$ (ISO) for the speech frequencies 500, 1000, and $2000 \mathrm{~Hz}$ was utilized with all children. Candidates who responded at this level for all three frequencies in each ear were utilized as subjects. Six children initially selected as candidates were eliminated from the study due to failure at one or more of the target frequencies. In addition, four children, all from the 2.5 to 3 year age group, did not respond to audiometric conditioning procedures. These children also were excluded from 
TABLE 6

MEAN PPVT IQ EQUIVALENTS

LISTED BY AGE GROUPS

\begin{tabular}{|c|c|c|}
\hline Age Group & $\begin{array}{l}\text { Mean IQ } \\
\text { Equivalents }\end{array}$ & $\begin{array}{r}\text { Standard } \\
\text { Deviation }\end{array}$ \\
\hline 2.5 to 3 & 93.00 & 8.72 \\
\hline 3 to 3.5 & 98.30 & 9.95 \\
\hline 3.5 to 4 & 102.10 & 11.76 \\
\hline 4 to 4.5 & 103.50 & 15.25 \\
\hline 4.5 to 5 & 205.50 & 12.72 \\
\hline 5 to 5.5 & 109.60 & 9.89 \\
\hline 5.5 to 6 & 109.90 & 14.00 \\
\hline
\end{tabular}


participation in the study. In all cases where candidates failed either the PPVT or the audiometric screening, alternate subjects of the appropriate age and sex were selected.

\section{INSTRUMENTATION}

To determine mastery and acquisition of the phonemes $/ t /$ and $/ \mathrm{k} /$, an articulatory assessment procedure specific to the phonemes was devised. Following administration of the PPVT and the audiometric screening, each subject was presented six pictures to elicit the initial, medial, and final sound elements of phonemes $/ t /$ and $/ k /$. One picture was used for each sound element of each phoneme. An additional picture, designed to elicit the sound element medial $[t]$ in the word "skating," also was presented to each child. The purpose of this arrangement is discussed in Appendix E. Each picture was centered on $5^{\prime \prime} \times 8^{\prime \prime}$ cards and was designed to elicit a specific word. When verbalized, the target word resulted in the production of a specific sound element.

Target words were taken from the Developmental Articulation Test (Henja, 1955). Henja's words for $/ t /$ and $/ k /$ were chosen for two reasons: 1) all words were easily represented with pictures; and 2) target sound elements were not located in consonant blend contexts. Henja's word list also was selected because it included the eliciting word "potato" (for sound element medial $(t)$. When uttered, this word tends to result in stressing of the second syllable, thus, producing an audible and characteristic / $t /$. 
Test words and corresponding target sound elements for the phoneme $/ k /$ included "cat" to elicit $[k-J$; "chicken" to elicit [-k-]; and "book" to elicit [-k]. For the phoneme $/ t /$, target words included: "table" to elicit [t-]; "potato" to elicit [-t-]; and "coat" to elicit [-t].

The test procedure consisted of asking the subject to verbally identify each picture, thereby producing the target sound elements as they occurred in the eliciting word. The eliciting question, uttered by the Investigator while pointing to the appropriate picture, was "What is this?". Subjects' responses were recorded on the test record form (Appendix C) as correct or incorrect. Any errors in production (i.e., substitution, omission, or distortion) also were noted immediately following each child's response.

If the child was unable to verbally identify a specific picture, a procedure designed to elicit the target word while providing a minimum of auditory cues was initiated. Step one required the Investigator to utter a maximum of three eliciting sentences for each target sound element not produced in response to pictures. Each sentence was constructed so as to supply cues relative to the meaning of the target word. The word itself was not included in the sentence. The child's task was to complete the sentence by supplying the target word. Appendix $D$ includes a list of eliciting sentences used for each target word and sound element. If this technique failed to produce the desired word, a descriptive sentence related to the eliciting picture was read to the child. Each 
description included the target word, uttered without undue stress or intonation. As far as possible, the modeled word was placed near the middle of the descriptive sentence, so that it was preceded and followed by other words. In addition, each descriptive sentence was followed by another phrase; "Now you tell me: what is this picture?" This sentence was included to re-direct the child to the task of identifying the picture, and to also provide more intervening auditory stimuli between the modeled word and the child's response. A list of descriptive sentences used for each sound element is included in Appendix $D$.

Several children in the younger age groups did not respond appropriately to the first reading of the descriptive sentence. When this occurred, two further repetitions of this sentence and the task direction were given. If the child did not respond following the repetitions, he was dropped from the study and an alternate child was used. Two children in the 2.5 to 3 year age group and one child in the 3 to 3.5 age category were omitted in this fashion.

\section{Investigator Reliability}

Time and economy dictated that the Investigator make all judgements relative to correct production of $/ t /$ and $/ k /$ in words. This was especially true since all testing was conducted at the subjects' preschools. Therefore, to ensure that the Investigator was reliable as a judge of children's articulatory abilities regarding phonemes $/ t /$ and $/ \mathrm{k} /$, a pilot 
study was conducted.

Subjects for the pilot study were siblings of children seen for speech and language treatment at the Portland State University Summer Speech and Hearing Clinic (Summer 1973). Since the only goal was elicitation and judgement of instrumental speech sounds $/ t /$ and $/ k /$, auditory acuity, SES, and intelligence were not controlled. The 10 subjects (five males and 5 females) ranged in age from 3 years, four months, to 5 years, eleven months, with a mean age of 5 years, five months. Each child was presented all eliciting pictures described above. In addition, to determine the effectiveness of Templin's use of the word "skating" to elicit the sound element medial [t] (1957), subjects were shown a picture designed to elicit that word. All responses were recorded using an Ampex AG 500 tape recorder equipped with a lavaliere microphone suspended approximately 3 inches from the subject's mouth. Record speed was $7 \frac{1}{2}$ inches per second.

To establish the Investigator as a reliable judge regarding correct production of phonemes $/ t /$ and $/ k /$ in words, a panel of two Speech Pathologists experienced in articulation testing was recruited to listen to and judge the recorded responses. Their findings were compared with those of the Investigator. An agreement of 80 per cent or better on all sound elements recorded during the pilot study was the criterion for reliability.

The taped responses of the ten subjects (each child pro- 
duced 6 sound elements plus medial $[t]$ in "skating;" a total of 70 items) were played at the recorded speed using an Ampex 620 amplifier set at a volume level of 8 . The panel members were given the definition of correct production, presented in Chapter I, to assist them in deciding whether a specific sound element was used appropriately in a particular word.

Results produced an agreement between the three listeners of 92 per cent on all sound elements except medial $[\xi]$ in "skating." Since this particular item was not a major part of the developmental articulation test, the main investigation was begun with the Investigator as the sole judge of articulatory development of phonemes $/ t /$ and $/ k /$. The rationale for including the word "skating" in the main investigation as well as the specific procedure are reported in Appendix E.

\section{ANAIYSIS}

Upon completion of testing, developmental ages for each phoneme were assigned. The first step was to record the number and percentage of children in each age group who correctly produced each sound element and each phoneme. These data were used to compute age of mastery for sound elements and phonemes. secondly, the number and percentage of subjects who correctly produced at least two of three sound elements at each age level were recorded. These figures were used to compute age of acquisition for each phoneme. Data were also collected on two methodological problems, the presentation of modeled words and 
the responses of subjects to the eliciting word "potato."

\section{Mastery of Sound Elements and Phonemes}

A sound element was labeled as mastered at a particular age level if 75 per cent or more of the subjects within an age group correctly produced the target sound in words. For assigning developmental ages to phonemes, two operational definitions of mastery were used. The first definition required that three sound elements ( $I, M, F)$ of each phoneme be correctly produced in words by 75 per cent of all subjects in an age group. This requirement is identical to those of the three developmental studies discussed in Chapter II with regard to number of sound elements examined for each phoneme. Use of this criterion resulted in a set of developmental ages hereafter labeled set I. The second operational definition of mastery excluded the medial sound elements of both phonemes from analysis. In this case, mastery indicated that 75 per cent of all subjects correctly produced two sound elements (I,F) of each phoneme. The resulting ages from this analysis were labeled Set II.

Several factors contributed to the decision to include two separate sets of developmental ages for each phoneme, with one set excluding the medial sound elements from analysis. In the initial design of the study, it was decided to assign ages of mastery by limiting analysis to three sound elements of each phoneme ( $I, M, F)$ since the developmental ages previously assigned to phonemes $/ t /$ and $/ k /$ were established by 
utilizing this procedure (Wellman et al., 1931; Poole, 1934; and Templin, 1957). A review of the literature on articulatory assessment, however, indicated the controversy surrounding the concept of medial position and use of developmental ages assigned by utilizing this concept (see "Medial Position," Chapter II). As a result of the confusion surrounding medial position, Templin (1973) has suggested that developmental studies dealing with instrumental phoneme acquisition be concerned only with initial and final sound elements; those consonants which initiate or release a word. The suggestion was made especially with regard to voiceless plosives. According to Templin, when these sounds are uttered between two vowels, they are likely to be produced with voice. The resulting production may be an acceptable pronunciation within the culture, but will provide little information regarding the child's ability to produce the target sound. The common pronunciation of "skating," wherein the consonant / $t /$ is usually voiced, is an example of the above situation. Examining sound elements only as they initiate and terminate words removes some of the risk that the target may assume the characteristics of the surrounding phonetic environment.

An initial examination of results emanating from the present study also contributed to the decision to provide one set of developmental ages which excluded the medial sound elements. As noted previously, the word "potato" was chosen to elicit the sound element medial $[t]$ in the present study. The initiating consonant of the second syllable was designated 
as the medial $[t]$ sound element. In this context, the target was the initiating consonant of a stressed syllable. In the Investigator's opinion, the possibility that the sound would be produced with voice was thus diminished. When presented with the eliciting picture for "potato," 24 subjects (34 per cent) responded by eliminating the first syllable and pronouncing the word as "tato" or "tado." When uttered, this production tended to result in the addition of voice to the initiating consonant of the second syllable. In other words, 34 per cent of the judgements made regarding the presence or absence of medial. $\angle J$ in "potato" were based on a sound with different characteristics and in a different position than initially expected. The choice of this eliciting word will be discussed more fully in Chapter IV.

Mastery of phonemes $/ t /$ and $/ k /$ also was calculated by utilizing three sound elements ( $I, M, F)$ in the analytical process. The primary purpose of this procedure was to compare the resulting ages with the findings of Wellman et al. (1931); Poole (1934), and Templin (1957), all of whom utilized three sound elements when assigning ages of mastery to phonemes $/ t /$ and $/ \mathrm{k} /$.

Acquisition of Phonemes / $t /$ and / $/$

The individual test results were used to calculate ages of acquisition for each phoneme. A pioneme was listed as acquired if at least two of three sound elements were produced correctly by 51 per cent or more of the subjects in a particu- 
lar age group.

Target Words Presented by Modeling

Subjects who failed to respond to the pictures and eliciting sentences for each target word were provided with a descriptive sentence containing the target. Each target word requiring the descriptive sentence was labeled as "modeled." The words modeled for each child were recorded on the individual test record form. Upon completion of testing, the following information was recorded: 1) the number and percentage of total utterances which required modeling; 2) the number and percentage of modeled words for each age group; and 3) the number of instances each specific word required modeling. These data were compiled for the following reasons:

1. To determine the percentage of modeling required for all subjects;

2. To determine the percentage of modeling required by each age group;

3. To determine if a relationship existed between the need for words to be modeled and the age of the subject; and

4. To identify the specific words which most often required modeling.

Production of a Two-Syllable Form of the Eliciting word "Potato"

As previously noted, the eliciting word "potato" was produced by many subjects as "tato" or "tado." The frequency of this occurrence was calculated according to age groups to determine if a relationship existed between age and ability to use a three-syllable word. 
CHAPTER IV

RESULTS AND DISCUSSION OF RESULTS

RESULTS

The primary concern of the present study was to ascertain the probable order in which the phonemes / $/$ / and $/ \mathrm{k} /$ are mastered by children. A secondary purpose was to utiIize an alternative to the concept of mastery (Sander, 1972) to determine the ages at which children acquire the phonemes $/ t /$ and $/ \mathrm{k} /$. For purposes of reporting and discussing the results directly related to this investigation, the following subtopical headings will be utilized:

1. The order of mastery of phonemes $/ \mathrm{t} /$ and $/ \mathrm{k} /$, set one: ages calculated by including the medial sound elements;

2. The order of mastery of phonemes / t/ and / k/, set two: ages calculated by excluding the medial sound elements;

3. The order of mastery of sound elements initial $[\mathrm{Z}]$ and $\angle \mathrm{K}\rangle$;

4. The order of mastery of the remaining two sound elements of each phoneme; and

5. The order of acquisition of phonemes $/ \mathrm{t} /$ and $/ \mathrm{k} /$.

Additionally, data also were collected concerning two specific methodological problems posed by the study. First, findings relative to the method of eliciting the target response (i.e., modeling specific words) are reported below. Second, results of subjects' production of the word "potato," used to elicit the sound element medial $[\mathrm{t}]$, are reported. 
The order of Mastery of Phonemes $/ t /$ and $/ k /$, Set one: Ages Calculated By Including the Medial Sound Elements

Table 7 and Figure 1 list the percentage of subjects at each age level who correctly produced all sound elements $(I, M, F)$ of each of the two phonemes. For this analysis, criteria for mastery of a phoneme was the correct production of all three sound elements by at least 75 per cent of subjects studied. Thus, it is to be noted that the phoneme $/ \mathrm{k} /$ was mastered at age level 3 to 3.5 , while /t/ was not mastered at any of the age levels studied.

By applying Fisher's Exact Test (Zelditch, 1959) it was found that at three age levels out of seven the probability that differences could be attributed to chance were small (Table 7). At the age level of 2.5 to 3 , the difference was very significant $(p=.001)$. At the age level 3 to 3.5, the difference was significant $(p=.027)$, and at the age level 4.5 to 5 the difference once again was significant $(p=.002)$

The Order of Mastery of Phonemes $/ t /$ and $/ k /$, Set Two: Ages Calculated By Excluding The Medial Sound Elements

The percentage of subjects who correctly produced the initial and final elements of each phoneme are presented by age level in Table 8 and Figure 2. In this case, mastery was indicated if correct production of the two sound elements equaled or exceeded 75 per cent. Phoneme $/ \mathrm{k} /$ was correctly produced by the required percentage of subjects at the 2.5 to 3 year level. Criteria for the production of the 
TABLE 7

PERCENTAGES OF CHILDREN AT EACH AGE IEVEL WHO CORRECTLY PRODUCED AIL SOUND ELEMENTS OF EACH PHONEME

\begin{tabular}{l|c|c|c|c|c|c|c}
\hline \multirow{2}{*}{ Phoneme } & \multicolumn{7}{|c}{ Ages } \\
\hline & 2.5 & 3 & 3.5 & 4 & 4.5 & 5 & 5.5 \\
\cline { 2 - 7 }$/ \mathrm{t} / \mathrm{k} / \mathrm{k} /$ & 10 & 40 & 60 & 60 & 20 & 70 & 70 \\
& 70 & 90 & 80 & 90 & 80 & 100 & 90 \\
\hline
\end{tabular}

a Fisher's Exact Test $p=.001$

$b$ Fisher's Exact Test $p=.027$

c Fisher's Exact Test $P=.002$

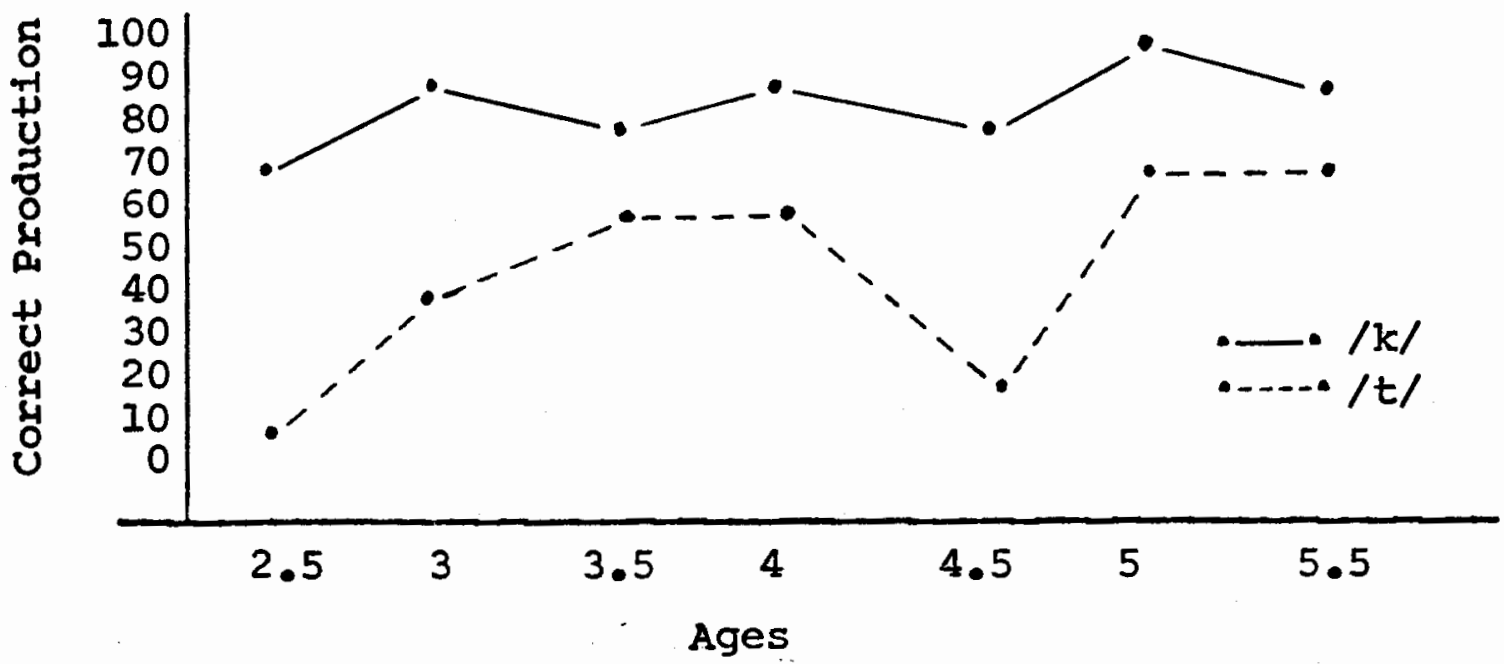
$\frac{\text { Figure I. A visual demonstration of the data presented in }}{\text { Table } 7}$ 
TABLE 8

PERCENTAGE OF CHILDREN AT EACH AGE LEVEL WHO CORRECTLY PRODUCED TWO SOUND ELEMENTS

(INITIAI AND FINAL) OF

EACH PHONEME

\begin{tabular}{l|c|c|c|c|c|c|c}
\hline \multirow{2}{*}{ Phoneme } & \multicolumn{7}{|c}{ Ages } \\
\hline \multirow{2}{*}{$/ \mathrm{t} /$} & 2.5 & 3 & 3.5 & 4 & 4.5 & 5 & 5.5 \\
\cline { 2 - 7 } & 50 & 60 & 80 & 80 & 40 & 70 & 70 \\
\hline
\end{tabular}

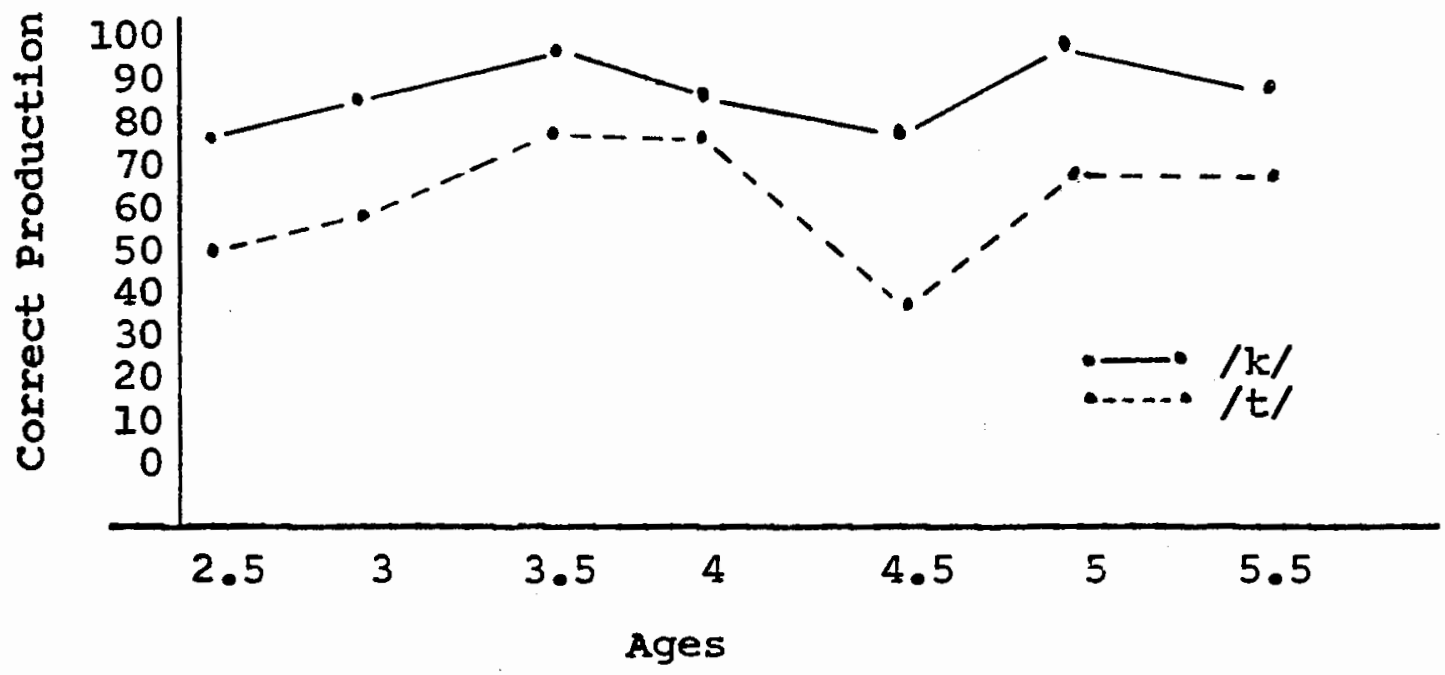

Figure 2. A visual demonstration of the data presented in Table 8 
$/ t /$ phoneme, however, was not met until the 3.5 to 4 year age level.

The order of Mastery of Sound Elements Initial $\langle z\rangle$ and $[k]$

In Table 9 are listed the percentage of correct productions by age group on all sound elements studied. Here it is to be noted that both sound elements initial [ $\overline{\text { J }}$ and [k] met criteria for mastery ( 75 per cent correct production) at age level 2.5 to 3 years.

The Order of Mastery of the Remaining Two Sound Elements of Each Phoneme

Examination of Table 9 reveals that the necessary percentage for the correct production of medial $[k]$ (75 per cent) was first achieved at the 2.5 to 3 year age level. Medial [ [] , on the other hand, was not mastered until the 4 to 4.5 year age level. Production of sound element final $[\mathrm{k}]$ met criteria at the 2.5 to 3 year level, while final [ $b]$ was mastered at age level 3.5 to 4 years.

The order of Acquisition of Phonemes $/ t /$ and $/ k /$

The percentage of children in each age group who correctly produced at least two of three sound elements of each phoneme is listed in Table 10 and Figure 3. A phoneme was considered to have met acquisition criteria when a minimum of 51 per cent correct production on two sound elements was achieved. Both phonemes $/ t /$ and $/ k /$ met the necessary requirements at the 2.5 to 3 year age level. 
TABLE 9

PERCENTAGE OF CHILDREN AT EACH AGE

LEVEL WHO CORRECTLY PRODUCED

EACH SOUND ELEMENT

\begin{tabular}{|c|c|c|c|c|c|c|}
\hline Age & & & Sound & lement & & \\
\hline & $\angle t=7$ & {$[-t-]$} & {$[-t]$} & {$[k-]$} & {$[-k=]$} & {$[-\mathrm{k}]$} \\
\hline 2.5 to 3 & 80 & 60 & 70 & 90 & 80 & 80 \\
\hline 3 to 3.5 & 100 & 50 & 60 & 100 & $100 *$ & 90 \\
\hline 3.5 to 4 & 100 & 70 & 80 & 100 & 80 & 100 \\
\hline 4 to 4.5 & 100 & 80 & 80 & 100 & 100 & 90 \\
\hline 4.5 to 5 & 90 & 60 & 40 & 100 & 100 & 80 \\
\hline 5 to 5.5 & 90 & 90 & 80 & 100 & 100 & 100 \\
\hline 5.5 to 6 & 100 & 100 & 70 & 100 & 100 & 90 \\
\hline
\end{tabular}

- For medial $/ t /$ and $/ k /, p=.015$ (Fisher's Exact Test) 
TABLE 10

PERCENTAGE OF CHILDREN AT EACH AGE LEVEL WHO CORRECTLY PRODUCED AT LEAST TWO

OF THREE SOUND ELEMENTS

(ACQUISITION)

\begin{tabular}{l|c|c|c|c|c|c|c}
\hline \multirow{2}{*}{ Phoneme } & \multicolumn{7}{|c|}{ Ages } \\
\hline \multirow{2}{*}{$/ \mathrm{t} / \mathrm{2.5}$} & 100 & 70 & 90 & 100 & 80 & 90 & 100 \\
\cline { 2 - 7 } & 90 & 100 & 100 & 100 & 100 & 100 & 100 \\
\hline
\end{tabular}

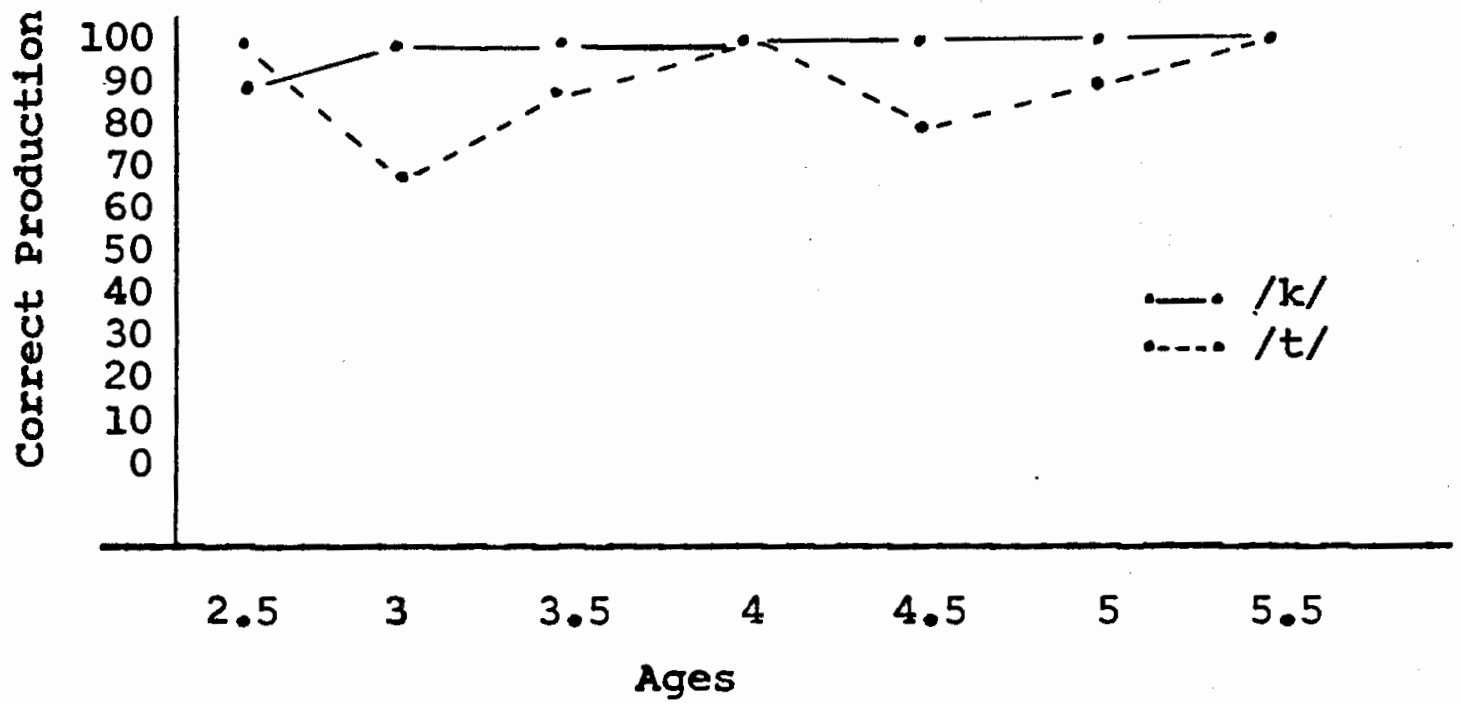

Fiqure 3. A visual demonstration of the data presented in Table 10 
Target Words Presented by Modeling. Target words used to elicit the sound elements were themselves elicited either pictorially or by modeling. Each of the seventy subjects in the sample produced seven words, regardless of the method used to elicit the target. Thus, 490 total utterances were recorded. The word "skating," used to elicit sound element medial [Z], was not utilized in the age-assigning process. It is included in the reporting of modeled words, however, since it was elicited at the same time and in the same fashion as the other target words.

The number and percentage of total utterances which required modeling is shown in Table 11. Results indicate that six per cent of all word presentations required modeling. The number and percentage of utterances requiring modeling at each age level is listed in Table 12. In this case, each age group included ten subjects with each producing seven words (a total of 70 utterances at each age level). At age level 2.5 to $3,18.6$ per cent of the subjects required the modeling of target words. This percentage generally decreased as the age of the subjects increased; children at the last age level ( 5.5 to 6 years) needed no target words modeled. Children under four years of age, on the other hand, required four times as much modeling. The number of instances in which each specific target word required modeling also was recorded. Examination of Table 13 indicates that the three target words requiring the most instances of modeling were those used to elicit the medial 
TABLE 11

NUMBER AND PERCENTAGE OF TOTAL UTTERANCES WHICH REQUIRED

MODELING

\begin{tabular}{lccc}
\hline $\begin{array}{c}\text { Total } \\
\text { Utterances }\end{array}$ & $\begin{array}{c}\text { Total } \\
\text { Subjects }\end{array}$ & $\begin{array}{c}\text { Number Modeled } \\
\text { Utterances }\end{array}$ & Percentage \\
\hline 490 & 70 & 33 & 6.73 \\
\hline
\end{tabular}


TABLE 12

NUMBER AND PERCENTAGE OF UTTERANCES

WHICH REQUIRED MODEI,ING

LISTED BY AGE

LEVEL

\begin{tabular}{|c|c|c|c|c|}
\hline Age & $\begin{array}{c}\text { Total } \\
\text { Utterances }\end{array}$ & $\begin{array}{l}\text { Number } \\
\text { Subjects }\end{array}$ & $\begin{array}{l}\text { Number } \\
\text { Modeled Words }\end{array}$ & Percentage \\
\hline 2.5 to 3 & 70 & 10 & 13 & 18.6 \\
\hline 3 to 3.5 & 70 & 10 & 7 & 10 \\
\hline 3.5 to 4 & 70 & 10 & 7 & 10 \\
\hline 4 to 4.5 & 70 & 10 & 3 & 4.3 \\
\hline 4.5 to 5 & 70 & 10 & 1 & 1.4 \\
\hline 5 to 5.5 & 70 & 10 & 2 & 2.9 \\
\hline 5.5 to 6 & 70 & 10 & 0 & 0 \\
\hline
\end{tabular}


TABLE 13

INSTANCES OF MODELING REOUIRED FOR

EACH TARGET WORD, IISTED BY

AGE LEVEL

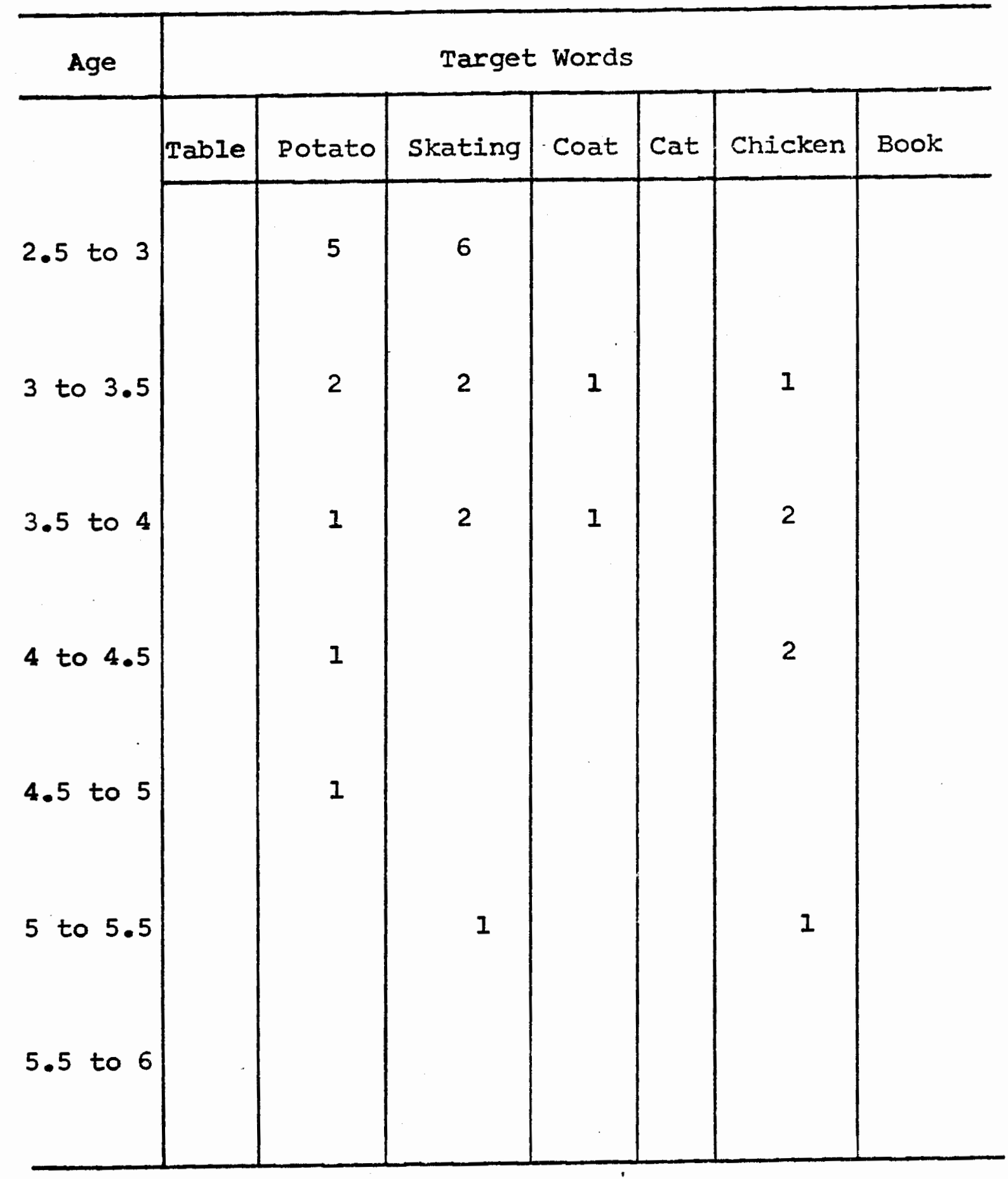


sound elements. It is to be noted also that the two words utilized to elicit the initial sound elements of each phoneme required no modeling.

Production of a Two-Syllable Form of the Eliciting Word "Potato." Judgement of the status of sound element medial [t] required that each child produce the eliciting word "potato." In Table 14 is listed the number and percentage of subjects in each age group who responded to the eliciting picture or descriptive (modeled) sentence by producing a two-syllable form of the target word ("tato or tado"). The percentage of subjects who used a two-syllable form of "potato" decreased with age, from 60 per cent at ages 2.5 to 3 , to zero at 5.5 to 6 .

\section{DISCUSSION}

This study, as previously noted, has sought to examine two observations made by Menyuk (1972) regarding the development of the phonemes $/ t /$ and $/ k /$. It is to be recalled that Menyuk proposed two hypotheses relative to $/ \mathrm{t} /$ and $/ \mathrm{k} /$. They were: 1) the child acquiring the phonological system of American English must learn to instrumentally use the phoneme / $t /$ before the phoneme / $/$ / can be learned; and 2) that the sound element initial [ $[\succeq]$ is mastered at an earlier age than initial $4 \mathrm{~kJ}$. These observations are discussed below in light of the results from the present study. The order of Mastery of Phonemes $/ t /$ and $/ k /$. 
TABLE 14

NUMBER AND PERCENTAGE OF CHILDREN IN

EACH AGE GROUP WHO RESPONDED WITH

A TWO-SYLLABLE FORM OF THE

ELICITING WORD "POTATO"

\begin{tabular}{|c|c|c|}
\hline Age & Number & Percentage \\
\hline 2.5 to 3 & 6 & 60 \\
\hline 3 to 3.5 & 6 & 60 \\
\hline 3.5 to 4 & 5 & 50 \\
\hline 4 to 4.5 & 3 & 30 \\
\hline 4.5 to 5 & 3 & 30 \\
\hline 5 to 5.5 & 1 & 10 \\
\hline 5.5 to 6 & 0 & 0 \\
\hline
\end{tabular}


Menyuk (1972) has theorized that the phoneme / $t /$ is necessary for development of the phoneme $/ \mathrm{k} /$. The implication is that / $t /$ must be instrumentally learned by children before / $k$ / can develop. We have seen in Chapter II that evidence coilected by wellman et al. (1931) and Templin (1957) contradicts this hypothesis, since in these studies mastery of $/ \mathrm{k} /$ occurs before mastery of $/ t /$. The results of the present study do not support Menyuk's claim. As indicated above (see Table 7), findings from the present investigation show that the phoneme $/ k /$ is mastered before the phoneme $/ t /: / \mathrm{k} /$ at 3 to 3.5 years, and $/ t /$ beyond 6 years. It has already been noted under "Results" that Fisher's Exact Test (Zelditch, 1959) was applied to this data. At three age levels out of seven, the probability that differences could be attributed to chance was small (Table 7). At the age level 2.5 to 3 , the difference was very significant $(p=.001)$. At the age level 3 to 3.5 , the difference was significant $(p=.027)$. At the age level 4.5 to 5 , the difference was once again very significant $(p=.002)$. Since the trend line for differences exists uninterrupted throughout the study (see Figure 1 ), one might hypothesize that significance could have been found in all of the prefive year levels, had the sample sizes been larger.

When results from the present investigation are compared with findings from the three early developmental studies cited under a review of the literature, the age of mastery reported for $/ \mathrm{k} /$ in the present study is found to 
be the earliest age recorded for that phoneme (see Table 15). It is felt that the design of the present study cannot be held accountabie for the early age of mastery recorded for $/ \mathrm{k} /$. First, the requirements for mastery of a phoneme were identical to those of Wellman et al. (1931) and Templin (1957) in requiring 75 per cent correct production for each sound element. Secondly, the socioeconomic status of the children studied, although based only on occupation of the father, was taken from a middle range, excluding high and low values. A criticism which has often been raised concerning the early age of mastery for initial [ $t]$ recorded by Wellman et al. (1931), was that the apparently high socioeconomic status of the sample contributed to the early age of development for $[t-]$.

In the present investigation, the phoneme / $t /$ was not mastered at any of the age levels studied, although percentage of correct production was 70 per cent in each of the last two age levels. It is speculated that had another age level been incorporated, mastery of / $t /$ might have been achieved. There are two factors which must be mentioned in connection with this finding: a marked decrease in correct production of $/ t /$ at the 4.5 to 5 year level, and the problem of testing sound element medial $[t]$.

It has been noted previously in Table 7 that the percentage of correct production for phoneme / $t /$ drops from 60 per cent at age level 4 to 4.5 to 20 per cent at age 4.5 to 5. No data are available which would indicate why this de- 
TABLE 15

COMPARISON OF THE AGES AT WHICH SUBJECTS

IN THE THREE DEVELOPMENTAL STUDIES

AND THE PRESENT INVESTIGATION

MASTERED / $/ \mathrm{AND} / \mathrm{k} /$ : SOUND

ELEMENTS AND PHONEMES

\begin{tabular}{|c|c|c|c|c|}
\hline \multirow{2}{*}{$\begin{array}{l}\text { Sound } \\
\text { Element }\end{array}$} & \multicolumn{4}{|c|}{ Investigator } \\
\hline & $\begin{array}{l}\text { Wellman } \\
\text { et al. (1931) }\end{array}$ & $\begin{array}{l}\text { Poole } \\
\text { (1934) }\end{array}$ & $\begin{array}{c}\text { Templin } \\
(1957)\end{array}$ & $\begin{array}{l}\text { Current } \\
\text { Investigation }\end{array}$ \\
\hline$[t=\bar{c}$ & 2 & 3 & 3 & 2.5 to 3 \\
\hline$[-t=]$ & 5 & 4.5 & 6 & 4 to 4.5 \\
\hline$[- \pm]$ & 3 & 3 & 3 & 3.5 to 4 \\
\hline$\angle k=\rangle$ & 3 & 4.5 & 3 & 2.5 to 3 \\
\hline$\angle-k=7$ & 3 & 3.5 & 3 & 2.5 to 3 \\
\hline$[-\mathrm{k}]$ & 4 & 3.5 & 4 & 2.5 to 3 \\
\hline $\begin{array}{l}\text { Phonemes } \\
\text { sound e }\end{array}$ & ts) & & & \\
\hline$/ t /$ & 5 & 4.5 & 6 & 5.5 to 6 \\
\hline$/ \mathbf{k} /$ & 4 & 4.5 & 4 & 3 to 3.5 \\
\hline \multicolumn{5}{|c|}{$\begin{array}{l}\text { Phonemes ( } 2 \\
\text { sound elements, } \\
\text { I\& F) }\end{array}$} \\
\hline$/ t /$ & 3 & 3.5 & 3 & 3.5 to 4 \\
\hline$/ k /$ & 4 & 4.5 & 4 & 2.5 to 3 \\
\hline
\end{tabular}


crease occurred. It is speculated, however, that had the percentage of correct production increased as it did at the previous 4 age levels, the required percentage of correct production for mastery of $/ t /$ might have been achieved within the age limits of this study.

Another factor which may have been involved in the late age of mastery recorded for the phoneme $/ t /$ in the present study was the problem of testing a sound element in the socalled medial position. It has been reported that the word selected to elicit medial $[€]$ in this investigation was expected to result in a characteristic example of $/ t /$ when customarily produced. It also was noted, however, that 34 per cent of subjects produced a form of this eliciting word which resulted in [ $t-]$ taking on some voicing characteristics. When this occurred, the sound element was listed as not correctly produced, thus, delaying the assigning of an age level for mastery. As will be seen in the next section, removal of the medial elements from the age-assigning process resulted in $/ t /$ being mastered at a substantially earlier age level (3.5 - 4 years; refer to Table 15).

The present study has emphasized the controversy surrounding the validity of assigning developmental ages by examining phonemes in the medial position. In light of questions surrounding medial position, this study was designed to calculate one set of developmental ages by excluding the medial elements from analysis. Since this data is available, it also is compared below with Menyul's hypothe- 
sis that $/ t /$ is necessary for the development of $/ \mathrm{k} /$.

When the data collected on the sound elements of medial $[t]$ and $\triangle S]$ in the present study were excluded from analysis of mastery, results indicated that phoneme $/ \mathrm{k} /$ was mastered before $/ t / ; / k /$ at age 2.5 to 3 , and $/ t /$ a year later, at 3.5 to 4 years. This is an interesting finding since it differs from the results of the three early developmental studies (Wellman et al., 1931; Poole, 1934; and Templin, 1957) when their data is manipulated to exclude the medial elements (see Table 15). The results are also of interest because they maintain the order of consonant development $(/ k /$ before $/ t /)$ which was established in the present study by including 3 sound elements $(I, M, F)$ in the analysis of mastery. It is the opinion of this Investigator that this finding also lends credibility to criticism of Menyuk's hypothesis that $/ t /$ must develop before $/ k /$. As long as the medial element is included in the analytical process of the present study, especially with respect to / $t /$, justified criticism can be leveled at the results that $/ k /$ is mastered prior to $/ t /$. This is true since testing phoneme development in the medial position has become a subject of controversy, and since it is currently viewed as a source of little practical information (Templin and Darley, 1969; and Templin, 1973). When the medial elements are excluded, however, the resulting developmental ages appear to take on more validity. This is especially true when one considers the three developmental studies, which may have assigned "artifical" ages 
of mastery to phonemes because of the delayed developmental ages of the medial sound element; a delay most likely caused by the particular eliciting word used, and not the "inherent difficulty" of the sound itself.

Mastery of Sound Elements Initial $[t]$ and Initial $[\mathrm{k}]$

Menyuk's second hypothesis was that sound element initial $[t]$ is mastered at an earlier age than initial $[k]$. As we have seen, support for this claim was based on the findings of Wellman et al. (1931), who reported mastery of $[t-]$ at 2 years, one year earlier than $[\mathrm{k}-]$ at three years. On the other hand, Templin (1957) reported both initial [t] and $[\mathrm{k}]$ were mastered at the same age, three years. This evidence was apparently overlooked by Menyuk. Results of the present study indicate that both initial $[t]$ and $[k]$ are mastered at the 2.5 to 3 year age level. Although these findings do not support Menyuk's claim, neither do they conclusively contradict it. Comparison of the present findings concerning initial $\triangle \Phi\rangle$ with results of the three developmental studies reveal that $\angle k-J$ is mastered earliest in the present study at 2.5 to 3 years (see Table 15). For initial [t], the three traditional studies report a range of ages for mastery from 2 years (Wellman et al.) to 3 years (Poole). The present investigation found initial $[t]$ mastered at 2.5 to 3 years, or at the earlier end of the age range reported by the three early studies (Table 15). The results of the current study regarding $[E-]$ and $[k-]$ agree 
most closely with those reported by Templin (1957), who reported mastery for $[t]]$ and $[k-]$ at 3 years. It is interesting to note that both the present study and that of Templin utilized the target word "table" to elicit initial [t] (Table 16).

Mastery of Sound Elements Medial and Final $/ t /$ and $/ k /$

A question posed by the design of this study concerned ages of mastery for sound elements medial and final $[t]$ and [k]. Although not specifically mentioned by Menyuk, these sound elements were essential in computing ages of mastery for phonemes. In the present study, medial $[€]$ was mastered at age 4 to 4.5 . This age is the earliest among the four studies compared (see Table 15). This finding can be explained partially be examining the word ("potato") used to elicit the sound element. As we have seen, this word, when customarily produced, tends to result in the production of a characteristic example of the / $t /$ phoneme as it initiates the second syllable of a word. It also was noted, however, that 34 per cent of all subjects altered this word by producing it with two syllables. The resulting acoustic product was usually a voiced allaphone of $/ t /$, and could be only scored as incorrect. In any event, the majority of all productions of medial $[t]$ (66 per cent) were made by subjects uttering a word with a phonetic environment which did not distort the medial sound element. The age of mastery for medial $L E]$ was, thus, based more on the subjects' ability to 
TABLE 16

TARGET WORDS UTILIZED IN THE THREE

DEVELOPMENTAL STUDIES AND THE

PRESENT INVESTIGATION

\begin{tabular}{|c|c|c|c|c|}
\hline $\begin{array}{l}\text { Sound } \\
\text { Element }\end{array}$ & \multicolumn{4}{|c|}{ Investigator } \\
\hline & $\begin{array}{l}\text { Weliman } \\
\text { et al. (1931) }\end{array}$ & $\begin{array}{l}\text { Poole } \\
(1934)\end{array}$ & $\begin{array}{l}\text { Templin } \\
\text { (1957) }\end{array}$ & $\begin{array}{l}\text { Current } \\
\text { Investigation }\end{array}$ \\
\hline$\angle t=]$ & bu & $\begin{array}{l}\text { tub } \\
\text { towel } \\
\text { toe } \\
\text { teeth } \\
\text { tape }\end{array}$ & $\begin{array}{l}\text { toes } \\
\text { table }\end{array}$ & table \\
\hline$[-t=]$ & pretty & $\begin{array}{l}\text { button } \\
\text { little }\end{array}$ & $\begin{array}{l}\text { skating } \\
\text { outing }\end{array}$ & potato \\
\hline$[-t]$ & $\begin{array}{l}\text { goat } \\
\text { hat }\end{array}$ & $\begin{array}{l}\text { velvet } \\
\text { elephant } \\
\text { that }\end{array}$ & $\begin{array}{l}\text { bat } \\
\text { skate }\end{array}$ & coat \\
\hline$\angle \mathrm{k}=\bar{\lambda}$ & $\begin{array}{l}\text { kite } \\
\text { cow }\end{array}$ & $\begin{array}{l}\text { cup } \\
\text { comb } \\
\text { card } \\
\text { cow }\end{array}$ & $\begin{array}{l}\text { cards } \\
\text { conduct }\end{array}$ & cat \\
\hline$E \mathrm{k}=7$ & cookies & chicken & $\begin{array}{l}\text { vacuum } \\
\text { cleaner } \\
\text { acorn }\end{array}$ & chicken \\
\hline$[-\underline{k}]$ & duck & $\begin{array}{l}\text { fork } \\
\text { block }\end{array}$ & $\begin{array}{l}\text { rake } \\
\text { truck }\end{array}$ & book \\
\hline
\end{tabular}


correctly produce the sound than on the effects of the eliciting word on that sound. For this reason, it is this Investigator's opinion that the age of mastery reported herein for medial [ $t]$ is more accurate than those previously reported (Wellman et al., 1931; Poole, 1934; and Templin, 1957). This Investigator also is of the opinion that the present reported age of mastery for medial $[t]$ would have been lower if all subjects had produced the full form of the eliciting word, thus, eliminating any effects of distortion caused by shortening the three-syllable word.

The sound element medial $[\mathrm{kJ}$ also is mastered in the present study at an earlier age than in any of the previous studies. Among the four studies compared, ages of mastery for medial $[\mathrm{k}]$ span one year, from 2.5 to 3 in the present study to 3.5 in Poole's study (see Table 15).

The only significant difference between medial $[t]$ and medial $[k]$, found by using Fisher's Exact Test (Zelditch, 1959) was at the age level 3 to $3.5(p=.015)$. At this age level, medial $[\mathrm{k}]$ was produced correctly 100 per cent of the time and medial [ $t]$ was produced correctly only 50 per cent of the time (see Table 9). This single finding, when paired with the data from the three developmental studies, would seem to add considerable credence to the belief that medial $[k]$ is mastered by children at an earlier age than medial $[\succeq]$.

Sound element final $[t]$ is mastered in the present study at age 3.5 to 4 years, the latest age reported in any 
of the studies compared (Table 15). A possible factor related to this finding lies in the Investigator's insistence that final sound elements be released with audiole aspiration.

Final $[K]$ was mastered in this study at age 2.5 to 3 , a year and six months earlier than the results reported by Wellman et al. (1931) and Templin (1957). Neither the data nor examination procedure provide any clues as to why this result might have occurred.

Acquisition of Phonemes $/ t /$ and $/ k /$

A secondary purpose of the present study was to present an alternative to the concept of mastery. As traditionally defined, it is often responsible for producing results which represent upper limits of the instrumental sound-learning process. The intent was to determine at what age level ". - a child is producing a sound correctly more often than he is misarticulating or omitting it (Sander, 1972, p. 59)." The term "acquisition" was used to describe this stage of sound learning, in relation to the two phonemes / $t /$ and $/ k /$. As reported under "Results," both phonemes $/ t /$ and $/ \mathrm{k} /$ were found to be acquired at the 2.5 to 3 year age level. The percentage of correct production for both sounds was well above the necessary 51 per cent required to meet acquisition criteria (see Table 10). The high percentage for both phonemes ( $t /, 100$ per cent; $/ \mathrm{k} /$, 90 per cent) at the 2.5 to 3 year level makes it interesting to speculate what 
results might have been obtained if younger age groups had been examined. It has been noted previously, when the definition of acquisition is applied to the data of Wellman et al. (1931) and Templin (1957), / $t /$ and $/ \mathrm{k} /$ meet criteria for acquisition at two years of age (Sander, 1972).

Developmental ages resulting from application of acquisition criteria to specific phonemes would seem to be most useful when accompanied in developmental tables or texts by the ages of mastery for the same phoneme. As Sander has suggested (1972), a single developmental table could be utilized to incorporate both age of acquisition and mastery for each phoneme examined. The information thus presented would provide the speech clinician or parent with an age range for sound development. A normative sound schedule, developed by Sander (1972) and incorporating average and upper limits of correct production, was presented in Chapter II.

\section{Medial Position}

The main focus of the current study was not directed toward a detailed analysis of the concept of testing phoneme development in the medial position within words. The questionable utility of the concept, however, as well as its demonstrated ambiguity and possible effects on previously reported developmental ages, has made it imperative that the problem be discussed. The issue also is considered here since medial position is of direct concern to this study in 
that one set of developmental ages for $/ t /$ and $/ k /$ was assigned by using the medial sound elements. The present section summarizes the material presented in Chapter II, presents current results relative to the medial position, and offers several opinions as to future use of assessing articulatory development in the medial position.

The question of medial position first arose in preparing the design of the current study when it was noted in the three developmental studies that the sound element medial [t] was the last element of / $t /$ to be mastered. The words used to elicit medial $[t]$ in these studies were examined, and it was found that without exception, each of the studies employed a word whose customary utterance produced a medial [t] which was either voiced, of formed but not released (see word list, Table 16). In either case, a characteristic /t/ was not produced. Keenan's discussion of medial position (1961) was used to present a description of a sound's relation to the syllable as a more accurate method of describing the position of a sound element within a word. Sources also were cited which either indicated the paucity of information to be gained by testing phonemes in the medial position (Templin, 1973), or gave examples of articulation tests which, for the most part, do not assess phoneme development in the medial position (Irwin and Mussleman, 1962; and Templin and Darley, 1969).

In the present study, the Investigator dealt with medial position relative to / $t /$ by first selecting a word to 
elicit medial [t] which would not distort the acoustic characteristics of $[-t-]$ when produced. The word selected was "potato," and the first consonant of the second syllable was designated as the medial sound element. When this word was pictorially or verbally presented to the subjects, 34 per cent responded by omitting the first syllable and producing the word as "tato" or "tado." Thus, the Investigator in this case was forced to score the / $t /$ which initiated the second syllable as medial [t], mainly to record a response from each subject on the medial elements. When this shortened form of "potato" was uttered, the consonant designated as medial $[€]$ was usually produced with voice, thus creating, in essence, the same problem posed by the eliciting words for medial $[t]$ used in the three early developmental studies. It is to be noted also, however, that the majority of subjects ( 66 per cent) responded with the desired three-syllable production of the eliciting word.

Age of mastery for the sound element medial $[t]$ in the present study was 4 to 4.5 years. Since 66 per cent of all subjects uttered the eliciting word, it is not known to what degree the age of mastery was affected by the distorted $[-t-]$ produced when the eliciting word was uttered with two syllables. In the present investigation, medial [ $[\overline{\text { was }}$ mastered at an earlier age than in any of the previous studies (Wellman et al., 1931; Poole, 1934; and Templin, 1957). In the opinion of the Investigator, this finding indicates that the eliciting word "potato," when uttered with three syl- 
lables, probably provides a characteristic example of the phoneme / $t /$ produced in the medial position. This hypothesis is based on the relationship discussed above and in Chapter II between the late ages of mastery assigned to medial $[t]$ by the three early developmental studies and the words used in these same studies to elicit the medial sound element. It has been pointed out that children's productions of the words used in the three early studies to elicit medial $[t]$ may have resulted in the distortion of that sound element. The late age of mastery assigned to medial $[€]$ by the three studies is felt to have resulted because the listeners could not easily hear a characteristic / $t /$, and not because of any "inherent difficulty" faced by children when producing the $/ t /$ phoneme in the middle of a word.

In conclusion, assessment of the development of phoneme / $t /$ in the medial position was by far the most perplexing problem with which the Investigator had to deal in this study. The difficulty with the chosen eliciting word has already been discussed, and will be further reviewed in the next section. Initially, this study was to have used two eliciting words for medial $[t]$ : "potato" and "skating." The second word, which also was used by Templin, was incorporated in order that its resulting sound element medial [t] could be compared in age with that of the same sound element produced in "potato." As we have seen, however, the lack of agreement among a panel of judges in the pilot portion to this study precluded use of this word, at least for 
the initial purpose. A possible solution to the problem of determining the presence of a characteristic / $t /$ in words such as "skating" is presented in Appendix E.

Regarding further use of the concept of the medial position, two proposals are offered here. For purposes of normative studies relative to articulation development, the Investigator feels the child's ability to use and differentiate a particular phoneme must be examined in depth. The research, in this case, might make use of the system proposed by Keenan (1961) where each sound is examined according to its relationship to the syllable (prevocalic, postvocalic, or intervocalic) and its position relative to the word or phrase (external or internal). This procedure omits the less-than-precise terms initial, medial, and final. If, on the other hand, the clinician is interested in the child's ability to correctly produce speech sounds, and especially if time is important, this Investigator recommends that speech sounds be examined only in the initial and final positions within words. This recommendation is made on the basis of the difficulty experienced with eliciting medial [t] in the present study, and also the opinions presented by Templin and Darley (1969) and Templin (1973).

\section{Target Words Presented by Modeling}

The methodological problem of eliciting the target word and resulting sound element also was not a primary concern of this study. As with the concept of medial position, 
however, the method of presenting the stimulus word became important when the study design was developed. This was especially true in regard to the question of possible effects upon developmental ages resulting from presenting verbal cues to subjects. Accordingly, in Chapter II, data were presented which indicated that in some studies test words which included the target sound were more often produced correctly when modeled than if the target word was represented with pictures. While most of these studies (Snow and Milisen, 1954; Carter and Buck, 1958; and Smith and Ainsworth, 1967) dealt with articulatory defective children ages six and older, kresheck and Socolofsky (1972) discovered essentially the same result when testing normal four year old subjects. Since Irwin (1972) and Templin and Darley (1969) irdicate the probability of some subjects requiring an auditory model in order to produce the desired sound, the present study planned for this contingency by designing a procedure to provide a verbal model only when absolutely necessary, and with a minimum of cues (see "Instrumentation," Chapter III). It was decided to record the total number and percentage of words modeled, the number and percentage of modeled words required at each age level, and the number of instances each specific word was modeled.

Each subject in the study produced seven words; a total of 490 utterances. Of this total, thirty-three or 6 per cent were modeled. Although the study was not designed to determine if differences resulted from providing an acoustic mo- 
del, it is the Investigator's opinion that the small percentage of subjects who required modeling of the stimulus word did not substantially affect the end product, i.e., ages of mastery for $/ t /$ and $/ k /$. The decreasing need to model words at each age level seems to indicate that the child's age is directly related to his ability to associate a visual stimuIus with its appropriate "meaning," and to express this "meaning" verbally. The results also could relate to the developing ability of the child to respond to "academic-like" situations, requiring attention to a stimulus and a response. It also was reported under "Results" that the three words which required modeling most often were the three eliciting words for the medial sound elements. Of these, "skating" and "potato," used to elicit medial $[t]$, required the highest percentages of modeling. The results obtained also indicated that these two words required the most modeling at the 2.5 to 3 year age level. There are at least three possible reasons for this finding. In the first place, one can speculate that these words are not yet in the vocabulary of the 2 to 3 year old child. secondly, it also is possible that the young subject recognized the picture but was not yet at a developmental level sufficient to allow him to verbally respond. This point has already been mentioned. Finally, one also wonders whether the pictures chosen to elicit these two words represented the optimum in terms of communicating visual cues. 
Production of a Two-Syllable Form of the Eliciting Word "Potato"

As previously noted, 34 per cent of all subjects produced the word used in the present study to elicit medial [ $t$ ] as "tato" or "tado," instead of "potato." The resulting problem of judging the medial $[t]$ thus produced has also been noted. In selecting "potato" to elicit medial $[t]$, careful consideration was given to the expected acoustic product, i.e., a characteristic example of the phoneme / $t /$ in the medial position. The number of syllables in the word, however, in relation to the ages of the subjects and their ability to produce three-syllable utterances, was not considered. Under "Results," it was noted that the child's ability to respond with the complete three-syllable form of "potato" appeared to increase in direct proportion to his age. This finding would appear to indicate that the younger children in this study were unable to produce three-syllable words without shortening the word in some fashion. Metraux (1950) has reported that the normally developing child below the age of 54 months " . . continues to shorten or telescope words and phrases (1950, p. 42)." In the present investigation, this tendency to shorten verbal units was true only for that word which contained three syllables. 


\section{CHAPTER $V$}

\section{SUMMARY AND IMPIICATIONS}

\section{SUMMARY}

Research in the area of children's instrumental articulation development has provided the speech clinician with schedules of speech sound development. These developmental tables list the ages at which the specific phonemes of the language are mastered by normal children. Such schedules tend to give the impression that certain sounds must be developed before others can occur. Menyuk (1972) has expressed a similar point of view regarding the phonemes / $t /$ and $/ \mathrm{k} /$. She has hypothesized: I) that the phoneme /t/ must develop before the phoneme $/ \mathrm{k} /$; and 2) that the sound element initial $[t]$ is mastered at an earlier age than initial [k]. The present investigation was designed to operationally test the validity of Menyuk's observations relative to $/ t /$ and $/ \mathrm{k} /$.

The primary purpose of this study was to determine the ages at which phonemes /t/ and /k/ are mastered by normally developing children, thereby obtaining the order in which these phonemes are learned. A secondary purpose was to present an alternative to the conçept of mastery of speech sounds by determining the ages at which children ac- 
quire the phonemes $/ t /$ and $/ k /$. Four specific questions were posed by this study:

1. Is the phoneme / $t /$ mastered before the phoneme $/ \mathrm{k} /$ ?

2. Is the sound element initial $[t]$ mastered before initial $[\mathrm{K} 7$ ?

3. What is the order of mastery of the remaining two sound elements of each phoneme?

4. What is the order of acquisition of the two phonemes?

Seventy children, ranging in ages from 2.5 to 6 years, were selected from Portland-area preschools to serve as subjects. They were selected on the basis of age, sex, socioeconomic status, auditory acuity, and intelligence. Each child was presented with pictures designed to elicit the phonemes $/ t /$ and $/ \mathrm{k} /$ in three positions within words: initial, medial, and final. All sound productions were judged as correct or incorrect by the Investigator. Ages of mastery were obtained for individual sound elements (initial, medial, and final) and for the "complete" phonemes / $t /$ and $/ \mathrm{k} /$. Mastery of a specific sound element of $/ t /$ or $/ \mathrm{k} /$ was indicated if 75 per cent of subjects within a given age group correctly produced the target sound. The phonemes $/ t /$ and $/ \mathrm{k} /$ were labeled as mastered if 3 sound elements (initial, medial, final) were correctly produced by 75 per cent of all subjects at a specific age level. Mastery of phonemes also was assessed by excluding the medial sound elements from analysis, thereby requiring correct production of two sound elements, initial and final, by 75 
per cent of a given age group. Acquisition was determined by noting the age where at least 51 per cent of the subjects correctly produced phonemes $/ t /$ and $/ k /$. Analysis of data from the present investigation produced the following results:

1. The phoneme $/ \mathrm{k} /$ was mastered at an earlier age than $/ t /, / k /$ at 3 to 3.5 years and $/ t /$ beyond 6 years. With the medial sound elements excluded from analysis, the order of mastery remained the same, $/ \mathrm{k} /$ prior to $/ t /$. In this case, however, the phoneme $/ \mathrm{k} /$ was mastered at age 2.5 to 3 , while / $t /$ was mastered at age 3.5 to 4 .

2. The sound elements initial $[t]$ and $[\mathrm{k}\rangle$ were mastered at the same age level, 2.5 to 3 years.

3. The sound element medial $[\mathrm{k}]$ was mastered at age level 2.5 to 3 years, while medial [t] was mastered at 4 to 4.5 years. Mastery of final $\angle \mathrm{k} J$ was achieved at 2.5 to 3 years, while final $[€]$ was mastered one year later, at 3.5 to 4 years.

4. Both phonemes $/ t /$ and $/ \mathrm{k} /$ met acquisition criteria at the same age level, 2.5 to 3 years.

In conclusion, results of the present investigation tend to contraindicate the observations made by Menyuk (1972) relative to mastery of phonemes $/ t /$ and $/ k /$. Menyuk's hypothesis that phoneme $/ t /$ is necessary for the development of $/ k /$ is not supported by the data from the present study. Results of this study also do not support the hypothesis that initial $[t]$ is mastered prior to initial $[\mathrm{kJ}$.

\section{IMPLICATIONS}

The present study has investigated the development of 
two phonemes in the speech of preschool children. Several suggestions regarding the design of future developmental studies are presented below.

The Investigator first suggests that the number of subjects examined in each age group be larger than ten. Time and econorny dictated use of a small sample in the present investigation. Statistical analysis could have been more efficiently used, however, if the sample had included more subjects.

The Investigator also suggests that future developmental studies exclude the medial elements from analysis of speech sound development. The problems of assessing the phoneme $/ t /$ in the medial position have been discussed above. It is felt that the information gained in the present study by utilizing medial position did not offset the methodological problems encountered.

It is further suggested that target words used to elicit speech sounds be appropriate to the age of the subjects. This suggestion is made especially with regard to the use of three-syllable words with young children. As reported in Chapter IV, the results of the present investigation were somewhat affected by younger subjects' inability to reproduce a three-syllable word.

A final suggestion regarding future developmental studies concerns the use of the concepts of mastery and acquisition. This Investigator feels that the development of speech sounds can be most effectively described by assigning 
an age range to specific phonemes, rather than a single age of mastery. As Sander (1972) has demonstrated, the concepts of mastery and acquisition can be used together to accomplish such a purpose.

The problem of determining the presence or absence of a characteristic / $t /$ in words such as "skating" and "pretty" has been discussed in Chapters II, III, and IV. The Investigator feels that certain procedures could be developed to determine the presence of a characteristic / $t /$ in such words. Several suggestions are presented in Appendix E. 


\section{BIBLIOGRAPHY}

Carter, E. T., and Buck, M. W., "Prognostic Testing for Functional Articulation Disorders Among Children in the First Grade." J. Speech and Hearing Dis., 23, 124-133 (1958).

Dunn, L., Peabody Picture Vocabulary Test. Minneapolis: American Guidance Service (1965).

Henja, R., Developmental Articulation Test. Madison, Wisconsin: College Printing and Typing (1955).

Irwin, J., Disorders of Articulation. New York: The BobbsMerrill Company, Inc. (1972).

Irwin, R. B., and Musselman, B., "A Compact Picture Articulation Test." J. Speech and Hearing Dis., 27, 36-39 (1962).

Keenan, J., "What is Medial Position?" J. Speech and Hearing Dis., 26, 171-174 (1961).

Kresheck, J., and Socolofsky, G., "Imitative and Spontaneous Articulatory Assessment of Four-Year-old Children." J. Speech and Hearing Res., 15, 720-728 (1972).

Menyuk, P., The Development of Speech. New York: The Bobbs-Merrill Company, Inc. (1972).

Metraux, R., "Speech Profiles of the Pre-School Child 18 to 54 Months." J. Speech and Hearing Dis., 15, 37-53 (1950).

Poole, I., The Genetic Development of the Articulation of Consonant Sounds. Unpublished Ph.D. Thesis, University of Michigan (1934).

Powers, M. H., "Functional Disorders of Articulation - Symptomatology and Etiology," in Travis (ed.), Handbook of Speech Pathology. New York: Appleton-CenturyCrofts (1957). pp. 707-768. 
Powers, M. H., "Functional Disorders of Articulation - Symptomatology and Etiology;" and "Clinical and Educational Procedures in Functional Disorders of Articulation," in Travis (ed.), Handbook of Speech Pathology and Audiology. New York: Appleton-Century Crofts (1971). Pp. 837-910.

Roe, V., "Functional Disorders of Articulation," in Johnson (ed.), Speech Problems of Children. New York: Grune and stratton (1950). pp. 76-100.

Sander, E.K., "When Are Speech Sounds Learned?" J. Speech and Hearing Dis., 37, 55-63 (1972).

Siegal, G. M., Winitz, H., and Conkey, H., "The Influence of Testing Instruments on Articulatory Responses of Children." J. Speech and Hearing Dis., 28, 67-76 (1963).

Smith, M. W., and Ainsworth, S., "The Effects of Three Types of Stimulation on Articulatory Responses of Speech Defective Children." J. Speech and Hearing Res., 10, 348-353 (1967).

Snow, $K_{\bullet}$, and Milisen, $R_{\bullet}$, "The Influence of Oral Versus Pictorial Presentation Upon Articulation Testing Results." J. Speech and Hearing Dis., Monogr. Suppl. 4, 29-36 (1954).

Taylor, J. T., "Screening Intelligence." J. Speech and Hearing Dis., 28, 90-91 (1963).

Templin, M., "Spontaneous Versus Imitated Verbalization in Testing Articulation in Preschool Children." J. Speech Dis., 12, 293-300 (1947).

Templin, M., "Speech Development in the Young Child: 3. The Development of Certain Language Skills in Children." J. Speech and Hearing Dis., 17, 280-285 (1952).

Templin, M., "Norms on a Screening Test of Articulation for Ages Three Through Eight." J. Speech and Hearing Dis., $18,323-331$ (1953).

Templin, M., Certain Lanquage Skills in Children. Minneapolis: University of Minnesota (1957). pp. 1-60.

Templin, M., Personal Communication. 1973.

Templin, M., and Darley, F. L., The Templin-Darley Tests of Articulation (2nd ed.). Iowa City: University of Iowa (1969). 
U. S. Bureau of the Census, Working Paper Number 15: Methodology and scores of socioeconomic status. Washington, D. C. (1963).

Van Riper, C., Speech Correction: Principles and Methods (4th ed.). Englewood Cliffs, New Jersey: PrenticeHall, Inc. (1963).

Wellman, B. I., Case, I. M., Mengert, I. G., and Bradbury, D. E., "Speech Sounds of Young Children." University of Iowa Studies in Child Welfare, Vol. 5, No. 2 (1931).

Winitz, $H_{\bullet}$, Articulatory Acauisition and Behavior. New York: Appleton-Century-Crofts (1969).

Zelditch, M., A Basic Course in Sociological Statistics. New York: Holt, Rinehart, and Winston (1959) . p. $28 \%$ 


\section{APPENDIX A}

\section{A IIST OF THE PRESCHOOLS UTILIZED \\ IN THE PRESENT INVESTIGATION}

1. Bright and Early Day School

Mrs. Thompson, Director

2. Northeast Christian Preschool and Day Nursery Charlene Boyce, Director

3. KinderLand Raleigh Hills

Mrs. Harter, Director

4. KinderLand Aloha

Mrs. Green, Director

5. The Iittle People's Place

Mrs. Moore, Director

6. Towne Carousell Day School

Mrs. Jenkins, Director

7. Fruit and Flowers Day Nursery

Mrs. Ousley, Director

8. Kinder College Kindergarten

IaVonne Kramer, Director

9. Parkrose Day Nursery

Mrs. Adams, Director

10. Volunteers of America Oregon Inc. Day Care Center Mrs. Brown, Director 


\section{APPENDIX B \\ INTRODUCTORY LETTER TO THE SELECTED PRESCHOOLS}

\section{TO WHOM IT MAY CONCERN :}

My name is Glenn weybright. I am a second-year graduate student in speech and hearing sciences at Portland State University expecting to receive my Master of Science degree in June, 1974. In partial fulfillment of that degree, I am now in the process of collecting data for my thesis on speech and language development in early childhood. This study was undertaken in an attempt to resolve an apparent conflict in the literature regarding the age of development of the specific speech sounds $/ t /$ and $/ k /$. The study is descriptive in nature, that is, existing characteristics (in this case, language and speech) will be studied and described. The purpose of this letter is to request your cooperation in allowing me to examine the speech and language development of some of the children enrolled in your programs.

For purposes of explanation, the project can be divided into the following three sections:

1) Location of a comparatively large group of children between the ages of 2.5 and six whose parents have occupations which are comparable to occupations of the majority of United States citizens (occupation in this study is used as an indicator of socioeconomic status; children are selected by occupation in an effort to control the influence that socioeconomic status might have on speech and language development). Although location will be done on an individual school basis, a total of ten schools will be involved.

2) Separation of the above group into age categories. From this group, which will include children from all ten schools, ten children in each six-month age range will be selected for a total of seventy children.

3) Testing. Each child in the above sample of seventy will be visited at his own school. To rule out hearing loss as a factor affecting study results, each child will be given a hearing screening using a portable audiometer 
from Portland State University. An auditory vocabulary test will also be administered to examine the effects of vocabulary size on speech development. Lastly, a speech development scale to determine mastery of the sounds $/ t /$ and $/ k /$ will be administered. Total test time is estimated at not more than thirty-five minutes per child.

Results of this project will be described in the written report of the study. It is not known at the present time whether the data will be published. However, in that event each school will be contacted and permission requested.

In conclusion I should note that every effort will be made to insure the anonymity of the children involved. Samples of speech and language will be referred to by numbers only, as will occupations. My chief advisor in this project is Dr. Robert $\mathrm{H}$. English whose comments and signature follow. If you have further questions, feel free to contact me by calling the speech and hearing sciences department at 2293533. Also, you may reach me at home at 228-7816.

Thank you for your consideration of my request.

Sincerely yours,

Glenn Weybright

\section{STATEMENT OF ADVISOR}

As Director of the Program in the Speech and Hearing Sciences, Department of Speech, Portland State University, I approve the above statement of Glenn Weybright. Additionally, as chairman of his thesis committee, I am in full accord with this most worthwhile developmental project. In this study, as in all studies we undertake, strict confidentiality will be maintained.

Signed:

Robert H. English, D. Ed. Director, Program in the Speech and Hearing Sciences 
APPENDIX C

TEST RECORD FORM

Number:

Schools:

Birthdate: Age Group:
Parent's Occupation Score:

Peabody Test Score:

Audiometric Screening: pass no pass

Sound Tested Sound Element Test Words Response Type Error

$\begin{array}{lcl}\mid t / & t- & \text { table } \\ & -t- & \text { potato } \\ & -t & \text { coat } \\ k / & -k- & \text { cat, kitty } \\ & -k & \text { chicken } \\ & & \text { book }\end{array}$

Summary of Sound Development (circle one):

$/ t /$ : mastered ( 3 sound elements correct) acquired ( 2 of 3 sound elements correct) not developed (less than 2 sound elements correct)

$/ \mathrm{k} /$ : mastered ( 3 sound elements correct) acquired ( 2 of 3 sound elements correct) not developed (less than 2 sound elements correct)

Specific Words Which Required Modeling: 
APPENDIX D

ELICITING AND DESCRIPTIVE SENTENCES

FOR EACH TARGET WORD

Target Word

1. Table

2. Potato

3. skating

\section{Eliciting And Descriptive Sentences}

Eliciting Sentences:

a. In our kitchen, there are four chairs and a big

b. When we eat dinner, we sit at a

c. We put chairs around the

Descriptive Sentence:

d. Here is a table that is not very big. Now you tell me; what is this picture?

Eliciting Sentences:

a. Sometimes for Sunday dinner we have gravy and mashed

b. This is something to eat. We can mash it, or bake it, and we eat it with butter and salt. It's called a

c. This is what french fries are made from. It's called a

Descriptive Sentence:

d. This potato will soon be peeled and cooked. Now you tell me; what is this picture?

Eliciting sentences:

a. What's the fox doing?

b. The fox is having fun. What is he doing?

c. This fox is going very fast. Look at his feet and tell me what he is doing.

Descriptive sentence:

d. This fox is skating very fast. Now tell me; what is this picture? 
4. Coat

5. Cat

6. Chicken

7. Book
Eliciting Sentences:

a. What is the man wearing?

b. When you go outside to play in the snow, you wear a big heavy

c. In the winter, to keep warm outside, I wear a warm

Descriptive sentence:

d. Mr. Jones bought this coat at the store. Now tell me; what is this picture?

Eliciting Sentences:

a. Some people like dogs, and some people like

b. He drinks milk, he's soft and cuddly, and he says "meow." He is a

c. This is not a dog; this is a

Descriptive Sentence:

d. This cat is yellow and has green eyes. Now you tell me; what is this picture?

Eliciting Sentences:

a. On picnics, we eat potato salad and brown beans, and fried

b. At the farm, we see cows and horses and ducks and

c. For Sunday dinner, Mother cooks fried

Descriptive Sentence:

d. Here is a mother chicken giving her babies a ride. Now you tell me; what is this picture?

Eliciting Sentences:

a. At school, we read from a

b. Mother reads a story from the big story

c. When she goes to school, your sister reads from a

Descriptive Sentence:

d. This book has many interesting stories. Now you tell me; what is this picture? 


\begin{abstract}
APPENDIX E
THE PRESENCE OR ABSENCE OF A CHARACTERISTIC

$/ t /$ IN THE WORD "SKATING"
\end{abstract}

An original goal of the present investigation was to include an analysis of the sound element medial $\left.\_t\right]$ as it is used in the word "skating." This procedure was designed to produce a developmental age for medial $\langle t\rangle$ which could be compared with the age of mastery found by Templin (1957) for the same sound element in the same word. The purpose was to compare the age produced in the present study with the age reported by Templin, to determine if the particular characteristics of medial $[t]$ in the word "skating" functioned to delay assigning of a developmental age to that particular sound element. In the pilot to the main investigation, however, the panel of judges and the Investigator reached an agreement level of only 45 per cent regarding the correct production of medial $[t]$ in the word "skating." According to the initial criterion (agreement of 80 per cent), this result indicated the Investigator could not function as the sole judge regarding medial $[t]$ in "skating."

The low level of agreement reached on medial $[t]$ in "skating," caused primarily by disagreement over the voicing characteristic of the sound element in question, raised an interesting methodological issue. It was decided to abandon 
the initial goal of assessing a developmental age for medial [t] in "skating," and concentrate instead on developing a method to produce better agreement between listeners as to the presence or absence of a characteristic/t/ in words such as "skating." Several methods to improve agreement were examined, including use of spectographic analysis and playing tape segments backwards. After examining and discarding these procedures, it was decided to play the pilot tape at half speed ( $33 / 4$ inches per second) to determine if reduced speed affected the listeners' perception of the sound. Using this method, the Investigator and one judge were in agreement 84 per cent of the time on the ten taped samples of the word "skating." It therefore was decided to record all productions of the word "skating" during the main investigation, in order that they might later be analysed at half speed by the panel of judges and the Investigator. It was also agreed to listen to the tape at its recorded speed ( $7 \frac{1}{2}$ inches per second), so that the two percentages of agreement might be compared. In both cases, the task of the panel and the Investigator was to determine the presence or absence of a characteristic/ $t /$ in the target word. By this arrangement it was hoped that a method of obtaining a clear sample of the production of medial $[t]$ in words like "skating," where / $t /$ is often voiced, could be developed. During the main investigation of development of phonemes $/ t /$ and $/ \mathrm{k} /$, productions of medial $[€]$ in "skating" were recorded using an Ar-tik model 414 tape recorder, with 
an Ar-tik AP 28 microphone positioned at a distance of 3 inches from the subject's mouth. The samples were recorded at a speed of $7 \frac{1}{2}$ inches per second. Sixty-three samples of the target word were collected ( 7 samples were eliminated, either because the target word was not clearly produced, or because it could not be elicited). At the conclusion of the main investigation, the resulting tape was played twice. The first analysis was made at the recorded speed $\left(7 \frac{1}{2}\right.$ inches per second); equipment included the Ar-tik recorder and an Ampex amplifier model 620, set at a loudness level of 4 . The second analysis required that the tape be played at $33 / 4$ inches per second, on a Sony 104A tape recorder set at a loudness level of 6 .

The analysis of medial $[t]$ in "skating" by the panel and the Investigator produced the following agreement levels. At $7 \frac{1}{2}$ inches per second, the listeners reached an agreement level of 36 per cent regarding correct or incorrect production of medial $[t]$ in "skating." At $33 / 4$ inches per second, an agreement level of 65 per cent was reached. To determine reliability of the listeners, ten samples of "skating" were randomly selected and again subjected to analysis at the two recorded speeds. At $7 \frac{1}{2}$ inches per second, the agreement level was 40 per cent, while at $33 / 4$ inches per second, the level was 70 per cent. In no case did agreement at half speed reach the established criterion of 80 per cent. It is noted, however, that agreement relative to correct or incorrect production of medial $\measuredangle t J$ was substantially higher when 
the tape was played at half speed.

In the Investigator's opinion, the procedure of playing the taped samples at a slower speed was helpful in determining the presence or absence of a characteristic / $t /$ in the word "skating." It is recommended that further research relative to this topic be conducted to ascertain the utility of the approaches outlined above. 